\title{
Projected Hydroclimatic Changes in Two Major River Basins at the Canadian West Coast Based on High-Resolution Regional Climate Simulations ${ }^{\mathscr{b}}$
}

\author{
ANDRE R. ERLER AND W. Richard PELTIER \\ Department of Physics, University of Toronto, Toronto, Ontario, Canada
}

(Manuscript received 5 December 2016, in final form 29 June 2017)

\begin{abstract}
The impact of anthropogenic climate change on water resources and flood and drought risk is of great interest for impact modeling and to inform adaptation strategies. Here an analysis of hydroclimatic changes in the Fraser and Athabasca River basins in western Canada is presented, based on an ensemble of climate projections, which have been dynamically downscaled to $10-\mathrm{km}$ resolution using the Weather Research and Forecasting Model in two configurations. The GCM ensemble comprises four independent integrations of the Community Earth System Model under the representative concentration pathway 8.5. Basin-integrated changes in the seasonal cycle of hydroclimatic variables, and the variability of water supply and flood and drought risk, are considered. It is found that fall and winter precipitation generally increase by $20 \%-30 \%$ toward the end of the century, while changes in summer precipitation are smaller and associated with high model uncertainty. Furthermore, a reduction in snowfall and an increase in evapotranspiration are projected. However, projected impacts on water resources east and west of the Rocky Mountains are quite different: in basins closer to the coast (west of the Rocky Mountains) higher temperatures lead to a transition from predominantly solid to liquid precipitation and a significantly weaker spring freshet, followed by drier summers. In the lee of the Rocky Mountains the spring freshet remains largely unaffected and in summer the increase in evapotranspiration (ET) is compensated by increasing precipitation, so that water balance changes appear to be small. It is further found that a shift in runoff seasonality near the coast may lead to significantly increased flood risk in fall.
\end{abstract}

\section{Introduction}

The impact of anthropogenic climate change on water resources and hydroclimatic extremes is of considerable interest to policymakers, industry, and the general public. As a consequence, considerable effort is being invested into climate change impact and adaptation studies, so as to inform long-term policy and investment decisions under a changing climate. These studies are by necessity inherently regional, because climate change impacts are affected by regional topography and land use; for water resource studies a natural scale for assessment is that of major river basins. Hydroclimatic projections that resolve regional differences at these scales are therefore highly relevant for water resource

Supplemental information related to this paper is available at the Journals Online website: https://dx.doi.org/10.1175/ JCLI-D-16-0870.s1.

Corresponding author: Andre R. Erler, aerler@atmosp.physics. utoronto.ca management (Maraun et al. 2010). Furthermore, there is considerable interest in the impact of anthropogenic climate change on extreme events, in particular hydroclimatic extremes such as large-scale floods and droughts (Herring et al. 2014; Stott 2015).

The region of interest for the analysis that will be presented here is the Pacific Northwest (PNW) and in particular the Canadian provinces of British Columbia (BC) and Alberta. The climate of BC, to the west of the Rocky Mountains, is maritime and dominated by strong orographic precipitation, especially in fall and winter in the Coast Mountains, while the climate of Alberta to the east, in the lee of the Rocky Mountains, is relatively dry and continental in nature (Mote and Salathé 2010; Burn 2008). This stark contrast is created by the proximity of the Pacific Ocean to the west and the rain shadow of the Rocky Mountains just to the east. Between the Coast Mountains and the Rocky Mountains lies the Interior Plateau (BC), which climatologically can be seen as intermediate between the two extreme opposite climates at the coast and in the prairies. Water resources in western Canada and the PNW are of significant 
economic importance: in $\mathrm{BC}$ the large amount of precipitation leads to very high runoff, in particular in spring, which is managed through dams and exploited for hydropower generation. The prairies of Alberta, on the other hand, are a major agricultural region, which partially relies on irrigation to maintain crop production. Therefore, hydro-climatological projections of the impact of climate change on these resources are of high interest to policy makers and stakeholders. However, because of the complex coast line and steep topography, the region presents significant challenges for hydroclimatological modeling and the resolution of current global climate models (GCMs) is generally not sufficient for this area. For this reason global climate projection need to be downscaled to scales at which important topographic features are resolved and that are relevant for impact modeling.

A computationally relatively inexpensive and therefore widely used method of downscaling is statistical downscaling (Maraun et al. 2010; Teutschbein et al. 2011), where statistical relationships between the observed and modeled historical climate are derived and then used to correct the future climate projections. However, the method has been criticized for the assumption of stationarity (i.e., the assumption that the derived statistical relationships do not change in a changing climate; Teutschbein and Seibert 2013). Since the climate system is known to have many nonlinear feedbacks, this is a strong assumption, which cannot be tested directly, since observations are only available for the current climate. Nevertheless, different forms of statistical downscaling are widely used in impact modeling (e.g., Kerkhoven and Gan 2011; Shrestha et al. 2012). Furthermore, statistical downscaling is also often employed as a means of bias correction, even if downscaling is not strictly necessary (Teutschbein and Seibert 2012).

Dynamical downscaling, on the other hand, aims to overcome the limitations of statistical downscaling by using dynamically consistent, physically based models for downscaling. The models employed are typically numerical weather prediction models, which are often modified to allow long-term climate simulations. This approach is significantly more expensive computationally than statistical downscaling, but it does not require the assumption of stationarity and fully accounts for regional feedbacks in the climate system (to the extent that the relevant physics are represented). This is the approach that is employed here.

The current state of the art in global climate modeling, which forms the basis for any form of downscaling, is represented by the GCMs participating in phase 5 of the Coupled Model Intercomparison Project (CMIP5). A summary of climate change projections for North America based on the CMIP5 ensemble is given in the latest IPCC report [Fifth Assessment Report (AR5); Christensen et al. 2014] and a regional analysis of CMIP5 projections for the PNW is given in Abatzoglou et al. (2014) and Rupp et al. (2017). There is general agreement between the models that winter precipitation in the PNW is expected to increase, whereas in summer the climate change signal is weak and there is not much agreement between models. The general pattern of change in summer appears to be a decrease in precipitation in the south and an increase in the north, with the transition running from the northwest to the southeast across western Canada between $50^{\circ}$ and $55^{\circ} \mathrm{N}$. The location of the transition is not consistent between models and there is evidence that it may depend on the resolution of the atmospheric model: it has already been documented in the IPCC report (Christensen et al. 2014) that the high-resolution atmosphere-only GCM ensemble of Endo et al. (2012) places the transition region in summer significantly farther south, projecting a precipitation increase in most of the region of interest, rather than a decrease. In Mearns et al. (2013) it is further shown that the North American Regional Climate Change Assessment Program (NARCCAP) ensemble of regional climate simulations also places the transition from wetting to drying in summer farther south than the CMIP3 GCM ensemble (the location of the transition is similar in CMIP3 and CMIP5; Christensen et al. 2014). These findings are also consistent with the results of Erler et al. (2015) and Erler and Peltier (2016), who employed a small ensemble of dynamically downscaled regional climate simulations of very high resolution $(10 \mathrm{~km})$ over the PNW. They noted that the high-resolution regional climate model (RCM) [the Weather Research and Forecasting (WRF) Model] places the transition between wetting and drying significantly farther south than the driving GCM [the Community Earth System Model (CESM)], resulting in an opposite change signal between the GCM and the RCM in most of western Canada. Furthermore Erler et al. (2015) have also demonstrated that the rain shadow of the Coast Mountains over the Interior Plateau is almost entirely absent in CESM (and remains underestimated in WRF). This may indicate that low-resolution global models are inadequate for simulating the effect of climate change in the region of interest, and climate projections based on global models have to be interpreted with caution. As a consequence, the results from impact studies using statistically downscaled global climate projections would be similarly questionable.

Here we extend the hydroclimatological analysis of Erler et al. (2015) using an expanded ensemble of high-resolution 
regional climate simulations. The ensemble is driven by a small initial-condition ensemble of four independent but identically configured global climate simulations with CESM under the representative concentration pathway 8.5 (RCP8.5) forcing scenario (i.e., the simulations only differ in their initial conditions). CESM is a state-of-the-art CMIP5 GCM (Gent et al. 2011) and has been consistently identified as one of the best-performing GCMs in the Pacific Northwest region (Rupp et al. 2017; Mote and Salathé 2010). The global initial-condition ensemble has been dynamically downscaled to $10-\mathrm{km}$ resolution using WRF version 3 (WRFV3) in two different physics configurations, which differ only in their moist physics parameterizations (cloud microphysics and convection scheme). Downscaling has been performed for a midcentury and an end-of-century period over western Canada. The mean climate of the CESM ensemble and one of the two WRF configurations up to the middle of the twenty-first century was previously discussed by Erler et al. (2015), and changes in precipitation extremes in the entire ensemble are documented in Erler and Peltier (2016). Other recent studies that have employed dynamical downscaling and are specifically relevant for the discussion here are those of Salathé et al. (2010), Šeparović et al. (2013), and Pollock and Bush (2013). In particular, Salathe et al. (2010), employing the WRF model at 20 - and $30-\mathrm{km}$ resolution, have demonstrated that the climate change signal in precipitation is significantly modified by topography and is therefore sensitive to resolution. Furthermore Salathé et al. (2014) applied the dynamically downscaled climate projections of Salathé et al. (2010) to a surface hydrological model [the variable infiltration capacity model (VIC)] for the Columbia River basin, which is located just to the south of the Fraser River basin. Their results show that the increase in fall precipitation seen in the dynamically downscaled climate projections, combined with a later transition from snow to rain due to warmer temperatures, translates into a significantly higher risk of flooding in fall. The question of flood risk, especially in $\mathrm{BC}$, will also be a central point of the analyses to be discussed herein.

Following Erler et al. (2015), we also focus our hydroclimatic analysis on the Fraser and Athabasca River basins (FRB and ARB, respectively), two economically important basins in western Canada. The headwaters of both basins are located in the Rocky Mountains; the FRB is located to the west of the Continental Divide, covers most of the Interior Plateau, and drains into the Pacific, and the ARB is located to the east, in the rain shadow of the Rocky Mountains, and drains into Lake Athabasca, which eventually drains into the Arctic Ocean via the Mackenzie River system. The FRB is located in British Columbia, while the ARB is located in the province of Alberta. The hydroclimatic analysis presented here will be based on basin-averaged surface fluxes and climatic state variables; integrated hydrologic modeling is beyond the scope of this study.

At the same time, the (surface) hydrologic modeling studies of Shrestha et al. (2012), Kerkhoven and Gan (2011), and Leong and Donner (2015) can provide a point of comparison for this study. The first two studies have already been discussed in Erler et al. (2015), and it was found that both studies predict significantly more drying in summer than is seen in the dynamically downscaled projections. This, however, is not surprising, because both hydrologic studies only employed statistically downscaled CMIP3 GCM output to force their surface hydrologic models: it has been pointed out above that the CMIP3 (and CMIP5) GCMs tend to project drier summers in the PNW than some higherresolution models. Leong and Donner (2015) employed CMIP5 GCM output to force their surface hydrologic model, and consequently their results for the ARB also echo those of Kerkhoven and Gan (2011). A recent observational study by Sauchyn et al. (2015) also found a trend toward decreasing streamflow in the Athabasca River. These studies will provide points of comparison for the hydrological analysis in this work.

The objective of this article is to document the possible impact of climate change on water resources as well as flood and drought risk in western Canada, based on high-resolution, dynamically downscaled regional climate simulations. Details concerning the experimental setup and the model configurations used in the three ensembles are provided in the next section (section 2). The general patterns of climate change in the three ensembles are outlined in section 3 , after the validation of the results compared to gridded observations is presented. The primary focus of this article is hydroclimatological change in the Fraser and Athabasca River basins, which is presented in section 4; in particular, changes to the seasonal cycle of basin-averaged water balance and fluxes are discussed. We conclude with an analysis of changes in the variability of water supply, as well as flood and drought risk in section 5 . Section 6 summarizes the main results of this study.

\section{Experimental design and datasets}

\section{a. Experimental design}

The analysis presented in this article is primarily based on two small ensembles of dynamically downscaled climate projections. Both RCM ensembles downscale the same set of four GCM simulations, but they employ different moist physics parameterizations 


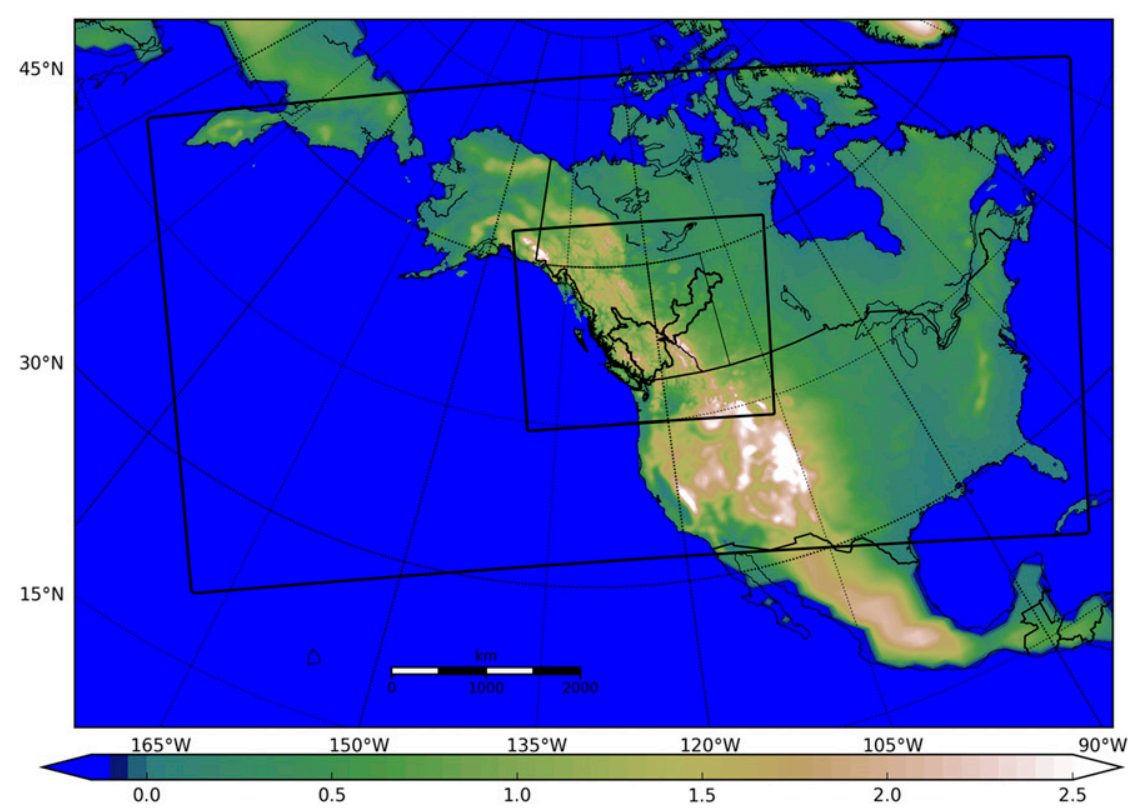

FIG. 1. Topography $(\mathrm{km})$ and outlines of the outer and inner WRF domains, as well as the outlines of the Fraser and the Athabasca River basins at the left and right in the inner domain, respectively. Note that the coastline indicated in the map represents the actual coastline at a resolution comparable to the inner WRF domain; it does not necessarily match the coastlines in the models.

in the dynamical model (the RCM). The GCM ensemble is an initial-condition ensemble, meaning that the model configuration is identical across the ensemble and the ensemble members differ only in their initial conditions. This makes a total of three different initial-condition ensembles, each of which comprises four identically configured members.

The global climate projections were generated using the CESM, version 1.04, in the standard CMIP5 configuration (Gent et al. 2011); see Erler et al. 2015 for details on how the ensemble was created. CESM is a fully coupled global climate model with interactive atmosphere, land, ocean, and sea ice components, and the nominal resolution of the standard configuration, which was employed here, is approximately $1^{\circ}\left(\approx 100 \mathrm{~km}\right.$ at $\left.50^{\circ} \mathrm{N}\right)$.

The RCM ensemble members differ in initial and boundary conditions (including sea surface temperatures and sea ice, which are prescribed from CESM). Each CESM ensemble member was separately downscaled over western Canada, using a nested configuration consisting of an outer and an inner domain. Large-scale spectral nudging was applied to the outer domain to reduce phase drift of the longest wavelength planetary waves between the global and the regional model. The outer domain covers most of North America and the North Pacific at a resolution of $30 \mathrm{~km}$, while the inner domain encompasses the Canadian provinces of British Columbia and Alberta, as well as parts of the surrounding territories, at a resolution of $10 \mathrm{~km}$. The outlines of the inner and outer domain as well as the topography at the respective model resolution are shown in Fig. 1 [adapted from Fig. 1 in Erler et al. (2015)]. This resolution is much higher than many gridded datasets and all available reanalyses. The regional simulations were performed for three 15-yr time periods: a historical validation period from 1979 to 1994, a midcentury period from 2045 to 2060, and an end-of-century period from 2085 to 2100 . Only one representative concentration pathway, the "business as usual" scenario (RCP8.5), was employed. In this scenario the $\mathrm{CO}_{2}$ and $\mathrm{CH}_{4}$ concentrations are $541 \mathrm{ppmv}$ and $2740 \mathrm{ppbv}$ in 2050 and $936 \mathrm{ppmv}$ and 3751 ppbv in 2100 , respectively.

We have chosen a time-slice approach with a small initial-condition ensemble in order to address the twofold problem of high internal variability and nonstationarity. Deser et al. (2012) have demonstrated that natural variability can be very large at regional scales, in particular for precipitation, so that many decades of data are necessary to obtain stable statistics. At the same time the process of anthropogenic global warming imposes a secular trend on the climate system with a time scale of also several decades. This means that time series data of sufficient length to obtain stable statistics (in a stationary climate) potentially stretch over several distinct climate states. As has been argued by Erler and Peltier 
(2016), it is possible to overcome this problem by combining the time-slice approach with an initial-condition (IC) ensemble: the 15-yr time slices employed for each period are short enough that climate statistics can be considered approximately stationary, while the sample size is increased through additional independent realizations from the IC ensemble. Whether 60 years of data are sufficient to obtain a stable climatology is not clear at this point; see Lucas-Picher et al. (2008) and Schindler et al. (2015) for further discussion.

The following definitions of seasons are used throughout this article: spring is March-May, summer is June-August, fall is September-November, and winter is DecemberFebruary. Occasionally the phrase "late summer" will be employed to refer to the period from July to September.

\section{b. WRF Model configuration}

One of the two WRF ensembles used in this study, as well as its mean climate up to midcentury, has been described previously in detail in Erler et al. (2015). In section 3 of this article the analysis of the mean climate will be extended to the end of the twenty-first century, so as to provide context for the basin-scale hydrological analysis presented later. The model release employed for downscaling is the Advanced Research WRF (ARW), version 3.4.1, to which a lake model (Gula and Peltier 2012; here employed in fully interactive rather than in offline mode) and code for time-dependent greenhouse gas (GHG) concentrations were added. The most important choices of physical parameterization schemes are as follows: the Noah land surface scheme (Tewari et al. 2004), the Morrison two-moment microphysics scheme (Morrison et al. 2009), the Rapid Radiative Transfer Model for GCM (RRTMG) radiation scheme (Iacono et al. 2008), and the Grell 3D ensemble cumulus scheme (Grell and Dévényi 2002). For more information on model setup, we refer the reader to Erler et al. (2015). This model configuration shows the best agreement with observations and will therefore also form the basis for most of the analysis presented here. However, in order to test the sensitivity to moist physics parameterizations, an alternate WRF ensemble will also be considered, and differences will be noted as appropriate. The configuration is identical to the first WRF ensemble, except that the Kain-Fritsch (KF) cumulus scheme (Kain 2004) and the WRF singlemoment 6-class microphysics scheme (WSM6; Hong and Lim 2006) were employed, as recommended in the WRF User Guide (Wang et al. 2012) for regional climate simulations. This WRF ensemble will be referred to as the alternate ensemble (AE), while the first WRF ensemble will be referred to as the IC ensemble or simply as the first WRF ensemble.

\section{c. Observational datasets}

To validate the historical model simulations against observations, several datasets have been combined into one high-resolution climatology. For precipitation and temperature in British Columbia the PRISM dataset (Daly et al. 2008) is employed, which has a resolution of $1 \mathrm{~km}$. This dataset has been obtained from the Pacific Climate Impacts Consortium (PCIC) and has been used wherever data are available (essentially BC). PRISM is an observational product that uses statistical relationships and a high-resolution digital elevation model (DEM) to estimate precipitation in mountain regions. In regions where PRISM was not available, the GPCC dataset (Schneider et al. 2013) at $0.25^{\circ}$ was used for precipitation and the $\mathrm{CRU}$ dataset (Harris et al. 2014) at $0.5^{\circ}$ for the remaining variables. To compute differences between model results and the observations, the observational datasets have been regridded to the respective model grid and merged in such a way that at each grid point the dataset with the highest resolution was used. Streamflow data has been obtained from the Water Survey of Canada (WSC). A more comprehensive description of the datasets can be found in section S1 of the supplemental material.

\section{Validation and climate change projections}

In this section an overview of the validation against historical observations as well as climate projections for western Canada will be presented. Results up to the midcentury period for CESM and the first WRF ensemble have already been published in Erler et al. (2015). Here we extend the results to the end-of-century period and also show the validation results for the alternate WRF ensemble alongside those for CESM and the first WRF ensemble.

Note that all numerical biases and temperature and precipitation changes reported in this section refer to averages over the area of the inner WRF domain, which is somewhat larger than the area shown in the maps. Unless otherwise noted, the high-resolution inner WRF domain is used. Also note that the observations used here can contain errors and biases; the artifacts visible in some of the difference plots are a result of the merging of datasets with different spatial coverage and resolution (see section S1 in the supplemental material for details). Furthermore, in the interest of space, this section will only be concerned with the ensemble means of the three initial-condition ensembles; a quantification of interannual and ensemble variability can be found in sections 4 and 5 . 


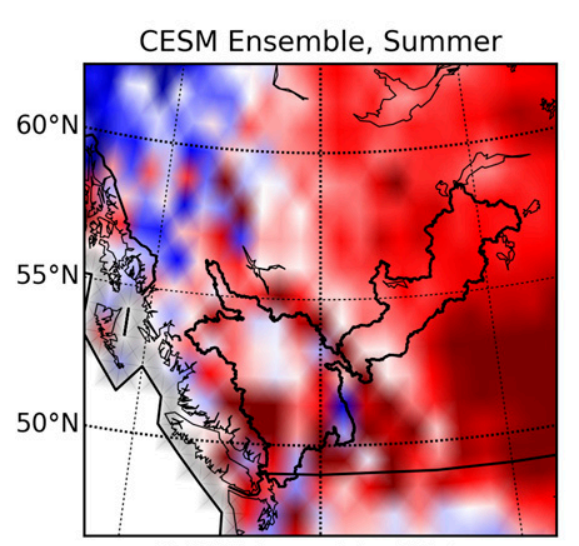

CESM Ensemble, Winter

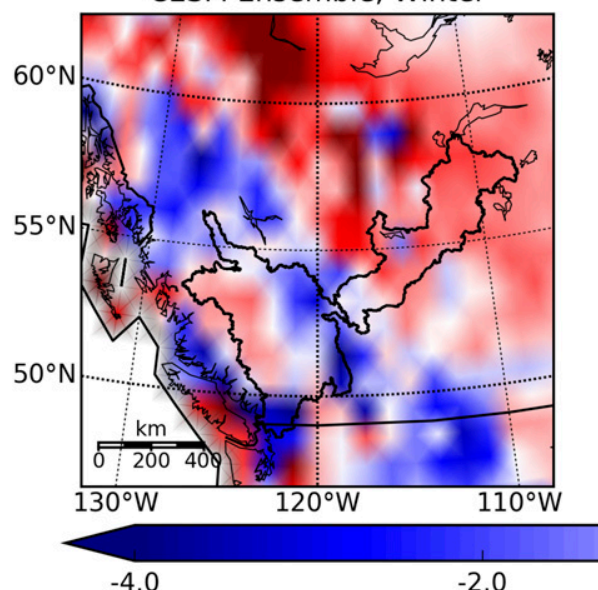

$-2.0$
2 m Temperature Differences [K] 1st WRF Ens. (10km), Summer

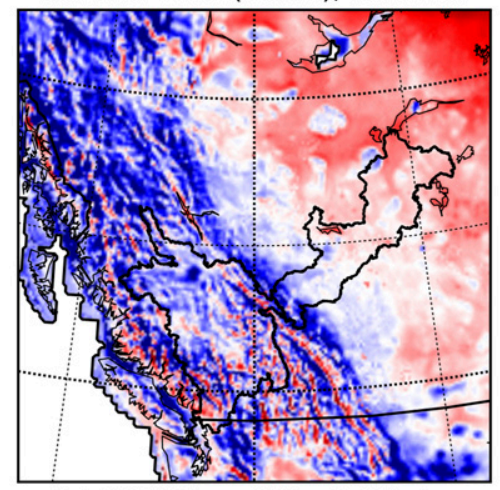

1st WRF Ens. (10km), Winter

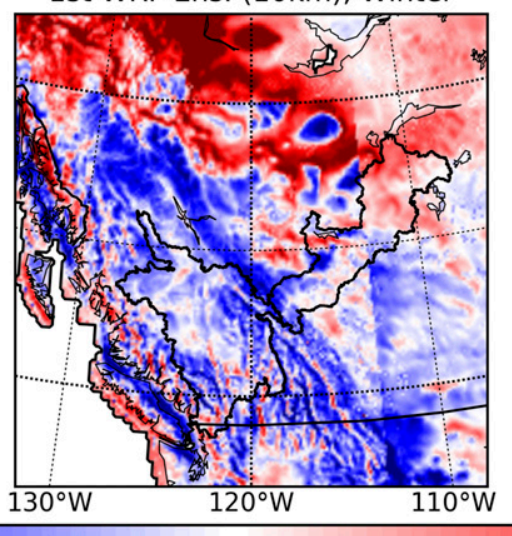

0.0

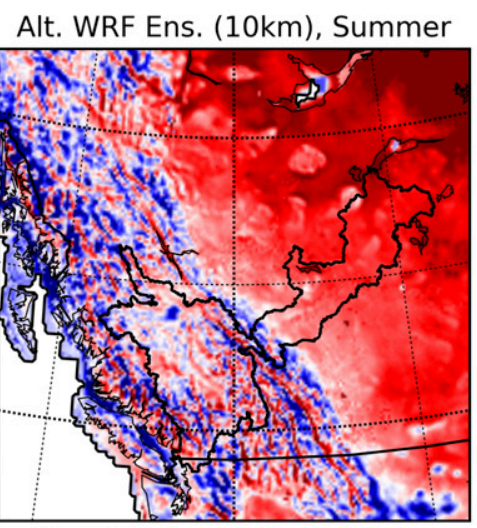

Alt. WRF Ens. (10km), Winter

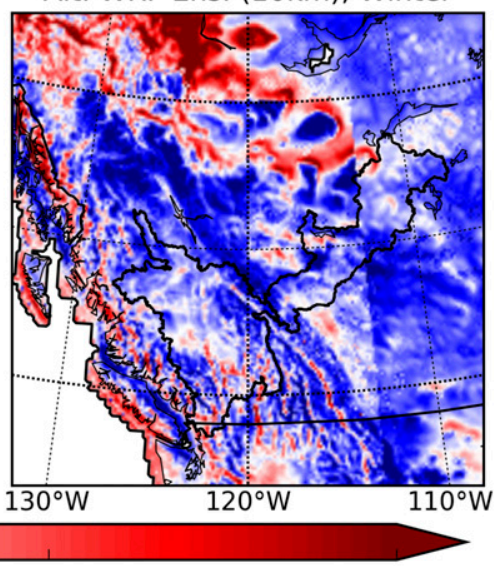

4.0

FIG. 2. Absolute 2-m air temperature bias with respect to (left)-(right) the merged observational dataset for the CESM ensemble, the first WRF ensemble, and the alternate WRF ensemble in (top) summer and (bottom) winter. Outlines of the FRB and ARB are shown in black.

\section{a. Validation against historical observations}

The absolute temperature bias for the three ensembles against the merged observational dataset is shown in Fig. 2. Seasonally averaged differences for summer and winter are shown in Fig. 2, top and bottom, respectively. The CESM ensemble is shown in Fig. 2, left, while the inner domains of the first WRF ensemble (Fig. 2, center) and the alternate WRF ensemble (Fig. 2, right) are shown also. The differences were computed on the native grid of each model ensemble; the merged observations have been reprojected and resampled for this purpose. It is evident that the temperature biases are strongly dependent on the season and vary strongly between models. A general trend visible in all models is a bias toward higher temperatures in summer in the northeast and a low bias in the Coast and Rocky Mountains in winter. Beyond that, CESM and the alternate WRF ensemble show a strong warm bias in the prairies in summer, while the first WRF ensemble shows a cold bias in the Coast and Rocky Mountains. Integrated over the land area of the inner WRF domain and all seasons, the average temperature bias in CESM is only $0.1^{\circ} \mathrm{C}$ despite large seasonal and regional deviations. The average temperature biases in the first and alternate WRF ensemble, on the other hand, are $-1.2^{\circ}$ and $-1.0^{\circ} \mathrm{C}$, respectively. The reason for the larger biases in WRF, despite the generally better representation of the seasonal cycle, is the existence of a strong cold bias (in excess of $3^{\circ} \mathrm{C}$ ) in both WRF configurations in spring, which is likely due to delayed snowmelt and has been discussed in Erler et al. (2015). In the alternate WRF ensemble this cold bias is partially compensated by the warm bias in summer. The distribution of annually averaged total precipitation in observations and in the three model ensembles is shown in Fig. S2 of the supplemental material. The spatial pattern in both models and observations is strongly dominated by orographic forcing superimposed on a large-scale gradient away from the coast. This results in very high 


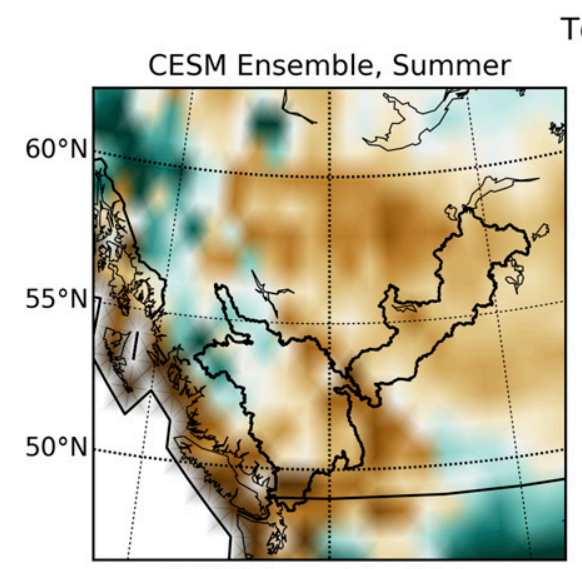

CESM Ensemble, Winter

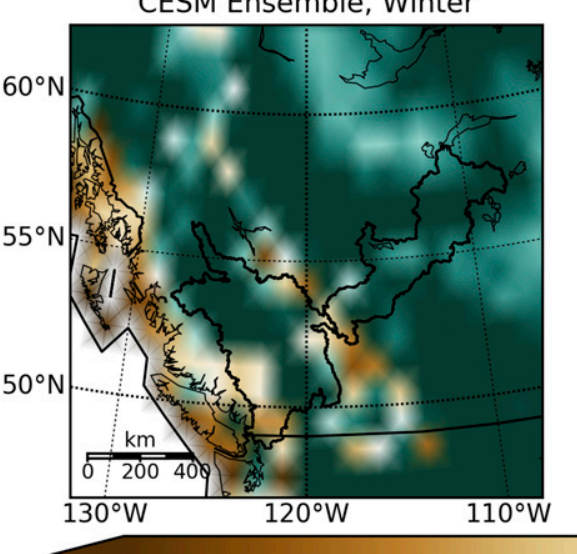

$\langle-40$

Total Precipitation Rate Fractions [\%]

1st WRF Ens. (10km), Summer

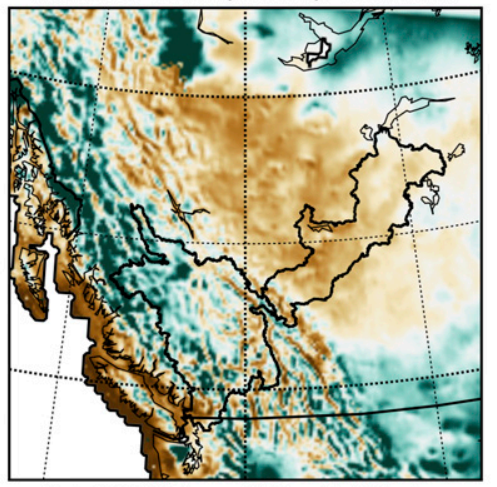

1st WRF Ens. (10km), Winter

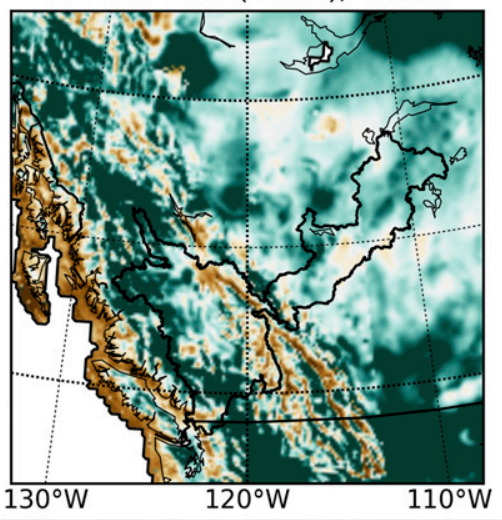

Alt. WRF Ens. (10km), Summer

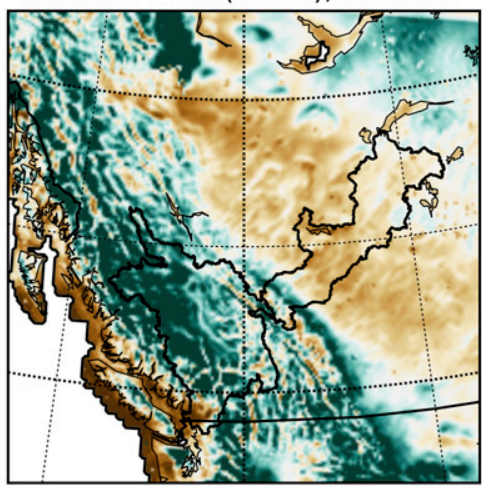

Alt. WRF Ens. $(10 \mathrm{~km})$, Winter

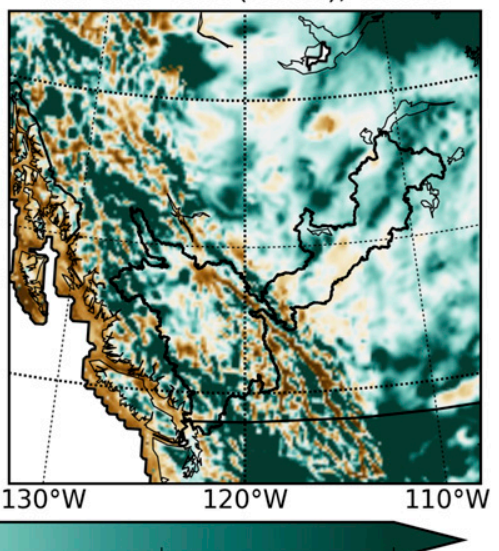

FIG. 3. As in Fig. 2, but for relative precipitation bias.

precipitation rates over the coastal mountain ranges and to a lesser extent the Rocky Mountains and much lower precipitation rates in their rain shadows over the interior plateau and the prairies. However, the representation of orographic precipitation is strongly dependent on model resolution: the rain shadow over the interior plateau is almost nonexistent in CESM, significantly improved in WRF at $30-\mathrm{km}$ resolution, and further improved but still underestimated at $10 \mathrm{~km}$. Averaged over the land area of the inner WRF domain and the annual cycle, the total precipitation bias in WRF is $8 \%$ and $13 \%$ in the first and alternate WRF ensembles, respectively. It is interesting to note that the bias in the driving CESM ensemble is only $3 \%$ due to compensation of negative and positive biases in summer and winter. Average biases for all seasons and averages over the area of the inner domain for the CESM ensemble and the inner and outer domain of the two WRF ensembles are shown in Table S1 of the supplemental material.

The relative precipitation bias in summer and winter is shown in Fig. 3 (same layout as Fig. 2). As has been pointed out previously, all models consistently underestimate precipitation intensities in the Coast Mountains (in all seasons). All models also underestimate the amplitude of the seasonal cycle of precipitation in the lee of the Rocky Mountains: there is a consistent dry bias in summer and a wet bias in winter. Evidently the bias in winter is significantly stronger in CESM than in WRF, presumably due to the representation of topography; however, it is worth noting that between the inner and outer domain in WRF the summer bias improves more with higher resolution. This is partly due to a general tendency toward higher precipitation in the inner domain (cf. Table S1), resulting in a better representation of the seasonal cycle and of orographic precipitation, but also a larger overall precipitation bias. Nevertheless, precipitation at the first rain barrier remains underestimated, even at 10-km resolution, and precipitation in the rain shadow is subsequently overestimated; this effect has been discussed extensively in Erler et al. (2015).

It should be noted that most of the orographic precipitation, which dominates the spatial pattern, falls as 
TABLE 1. The mean climate change response of the CESM and the two WRF ensembles averaged over the inner WRF domain and each simulation period; absolute changes for 2-m air temperature and relative changes for total precipitation are shown for the end-of-century and midcentury periods and for all seasons, as well as the annual average. For the CESM ensemble global mean changes are also shown.

\begin{tabular}{|c|c|c|c|c|c|c|c|c|}
\hline & \multicolumn{4}{|c|}{ End of century (2085-2100) } & \multicolumn{4}{|c|}{ Midcentury (2045-60) } \\
\hline & CESM (global) & CESM & IC ensemble & $\mathrm{AE}$ & CESM (global) & CESM & IC ensemble & $\mathrm{AE}$ \\
\hline \multicolumn{9}{|c|}{ 2-m temperature } \\
\hline Annual & $3.8^{\circ} \mathrm{C}$ & $5.2^{\circ} \mathrm{C}$ & $4.8^{\circ} \mathrm{C}$ & $4.8^{\circ} \mathrm{C}$ & $1.6^{\circ} \mathrm{C}$ & $2.4^{\circ} \mathrm{C}$ & $2.6^{\circ} \mathrm{C}$ & $2.8^{\circ} \mathrm{C}$ \\
\hline Summer & $3.8^{\circ} \mathrm{C}$ & $5.5^{\circ} \mathrm{C}$ & $4.5^{\circ} \mathrm{C}$ & $4.4^{\circ} \mathrm{C}$ & $2.0^{\circ} \mathrm{C}$ & $2.8^{\circ} \mathrm{C}$ & $2.3^{\circ} \mathrm{C}$ & $2.4^{\circ} \mathrm{C}$ \\
\hline Winter & $3.9^{\circ} \mathrm{C}$ & $5.4^{\circ} \mathrm{C}$ & $5.2^{\circ} \mathrm{C}$ & $5.1^{\circ} \mathrm{C}$ & $2.1^{\circ} \mathrm{C}$ & $2.7^{\circ} \mathrm{C}$ & $2.8^{\circ} \mathrm{C}$ & $3.0^{\circ} \mathrm{C}$ \\
\hline Spring & $3.7^{\circ} \mathrm{C}$ & $4.3^{\circ} \mathrm{C}$ & $4.4^{\circ} \mathrm{C}$ & $4.5^{\circ} \mathrm{C}$ & $2.0^{\circ} \mathrm{C}$ & $2.3^{\circ} \mathrm{C}$ & $2.4^{\circ} \mathrm{C}$ & $2.8^{\circ} \mathrm{C}$ \\
\hline Fall & $3.9^{\circ} \mathrm{C}$ & $5.4^{\circ} \mathrm{C}$ & $5.1^{\circ} \mathrm{C}$ & $5.2^{\circ} \mathrm{C}$ & $0.5^{\circ} \mathrm{C}$ & $1.6^{\circ} \mathrm{C}$ & $2.8^{\circ} \mathrm{C}$ & $3.0^{\circ} \mathrm{C}$ \\
\hline \multicolumn{9}{|c|}{ Precipitation } \\
\hline Annual & $6 \%$ & $9 \%$ & $17 \%$ & $14 \%$ & $3 \%$ & $5 \%$ & $9 \%$ & $7 \%$ \\
\hline Summer & $6 \%$ & $-4 \%$ & $9 \%$ & $8 \%$ & $3 \%$ & $-3 \%$ & $5 \%$ & $5 \%$ \\
\hline Winter & $7 \%$ & $14 \%$ & $17 \%$ & $12 \%$ & $4 \%$ & $7 \%$ & $11 \%$ & $7 \%$ \\
\hline Spring & $6 \%$ & $16 \%$ & $23 \%$ & $21 \%$ & $3 \%$ & $9 \%$ & $11 \%$ & $10 \%$ \\
\hline Fall & $6 \%$ & $12 \%$ & $18 \%$ & $17 \%$ & $3 \%$ & $6 \%$ & $7 \%$ & $8 \%$ \\
\hline
\end{tabular}

grid-scale precipitation in winter, which means that it is directly affected by model resolution and microphysics, but not by the cumulus parameterization. Summer precipitation, on the other hand, contains a considerable contribution from convective precipitation, which varies between $50 \%$ and $75 \%$ depending on the model configuration (however, the amount of convective precipitation does not appear to be sensitive to resolution). The alternate WRF ensemble, which employs different moist physics parameterizations, generally has somewhat higher summer precipitation over Canada (especially in the Rocky Mountains), but the spatial pattern in the lee of the Rockies is distinctly different from the observed pattern. In winter the alternate WRF ensemble has somewhat less excess precipitation over the Interior Plateau and the Canadian Prairies; there is some evidence in our simulations that the Morrison scheme produces too much low-intensity drizzle (at least in the version included in WRF release version 3.4.1).

It is interesting to note that the precipitation biases are generally more consistent between models than the temperature biases; biases are also more consistent in winter than in summer. This can likely be attributed to the dominance of large-scale weather patterns in winter, as opposed to local convection in summer, while the differences in temperature can potentially be attributed to differences in the treatment of land surface processes in CESM and WRF, specifically processes related to snow in winter and spring and evapotranspiration in summer. As noted in Erler et al. (2015), the spring temperature bias in WRF can be corrected by using the Canadian Land Surface Scheme (CLASS) snow model in the Noah Multiphysics (Noah-MP) land surface model or the Community Land Model. However, we also observe that the alternate WRF ensemble shows a significant warm bias in the prairies, despite the land surface model being the same in both WRF ensembles (the Noah land surface model). This temperature bias is very likely due to excessive solar (shortwave) radiation at the surface in the alternate WRF ensemble. In Fig. S3 of the supplemental material the relative solar radiation bias of the three models is shown: all three models tend to overestimate solar radiation compared to the observational climatology, whereas the bias in CESM and the first WRF ensemble is below $20 \%$ and is relatively consistent between the two models, the bias in the alternate WRF ensemble is consistently about twice as large (up to $40 \%$ ). Considering that the only difference between the two WRF ensembles is the representation of moist physics, the radiative flux difference is most likely caused by a difference in cloud cover (i.e., less cloud cover in the alternate ensemble). This hypothesis is also consistent with the fact that downward longwave radiation at the surface is somewhat higher in the first WRF ensemble (not shown; see section S2.3 in the supplemental material for more discussion).

\section{b. End-of-twenty-first-century projections}

The domain-averaged climate change signals for the CESM and the two WRF ensembles are shown in Table 1 (absolute changes for surface air temperature and relative changes for total precipitation); for CESM the global change signal is also shown. The global average warming of $3.8^{\circ} \mathrm{C}$ seen in the CESM ensemble is very close to the CMIP5 ensemble mean warming reported in the IPCC AR5 (Pachauri et al. 2014). The annual average warming averaged over the inner WRF domain is larger in CESM than in the two WRF configurations (5.2 $2^{\circ}$ vs $4.8^{\circ} \mathrm{C}$ in both WRF configurations), however, this difference is almost entirely explained by an approximately 

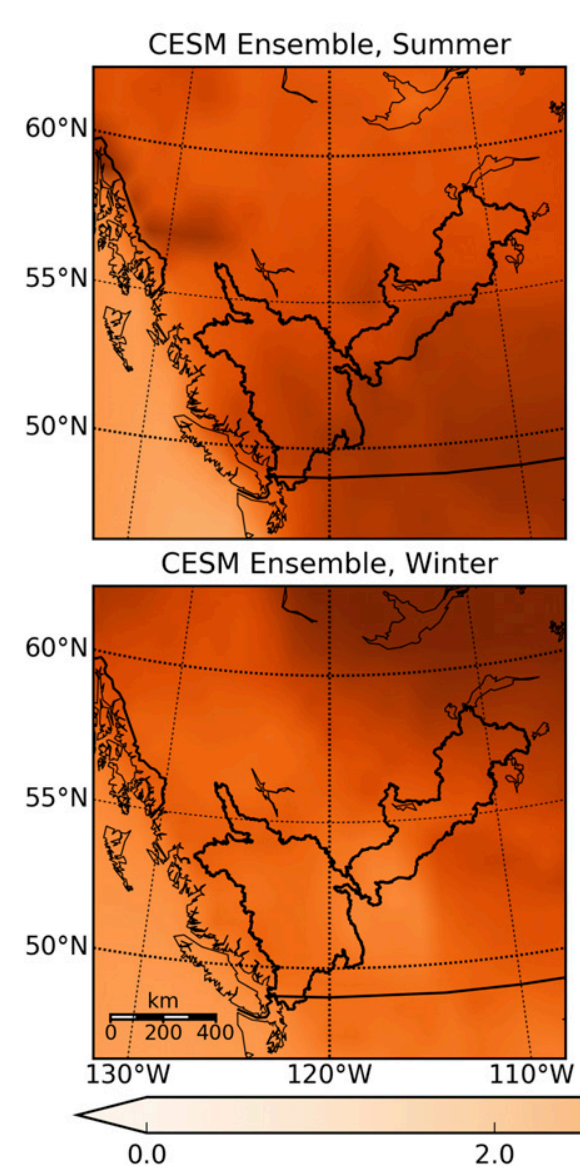

$2 \mathrm{~m}$ Temperature Differences [K] 1st WRF Ens. (10km), Summer

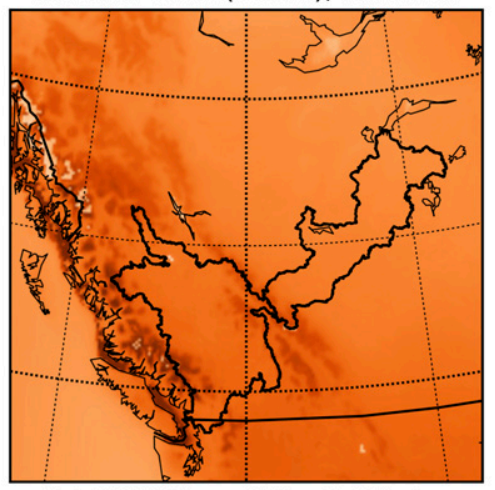

1st WRF Ens. (10km), Winter

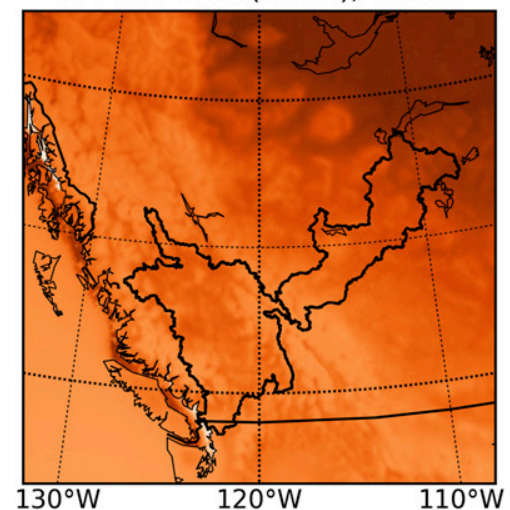

Alt. WRF Ens. (10km), Summer

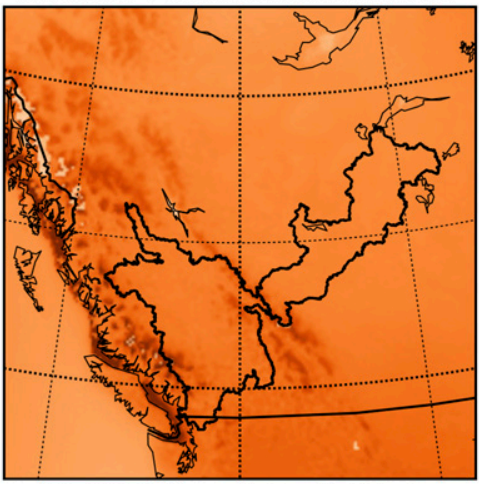

Alt. WRF Ens. (10km), Winter

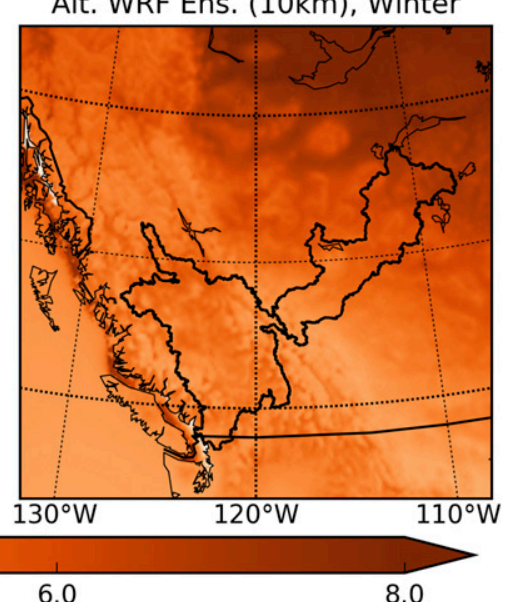

FIG. 4. Absolute changes in seasonal mean 2-m air temperature for (left)-(right) the CESM ensemble, the first WRF ensemble, and the alternate WRF ensemble in (top) summer and (bottom) winter. Changes are shown for the end of the twenty-first century relative to the historical period. Outlines of the FRB and ARB are shown in black.

$1^{\circ} \mathrm{C}$ difference in summer; in all other seasons, warming in CESM and the two WRF configurations is relative consistent. Figure 4 shows the end-of-century warming signal (average temperature differences between projection and validation periods, inner domain only; similar layout as Fig. 2). A significant difference exists between the magnitude and spatial distribution of warming between CESM and the two WRF configurations. Note, however, that the warming signal in the two WRF configurations is remarkably similar, despite the large differences during the historical period. During the other seasons, and in particular in winter, the warming signal is consistent between all three models. Furthermore all three are characterized by strong polar amplification in winter: approximately $3^{\circ} \mathrm{C}$ more than the domain average warming. In summer, on the other hand, warming is weaker at high latitudes $\left(\sim 2^{\circ} \mathrm{C}\right.$ below the domain average warming). This broad spatial pattern in summer is evident in all ensembles in summer; however, while the spatial pattern and the magnitude are highly similar in both WRF configurations, the magnitude of warming in summer is significantly larger in the CESM ensemble. In fact, in CESM over the Canadian Prairies warming in summer exceeds warming in winter, whereas WRF in general shows less warming in summer. The only regions where WRF shows stronger warming in summer (in excess of $6^{\circ} \mathrm{C}$ ) are high-elevation regions and some coastal regions. As discussed in Erler et al. (2015), the latter might have been caused by a sea ice interpolation error, while the former can likely be attributed to enhanced snow-albedo feedback due to receding snow cover at high elevations in summer; in winter and spring this effect operates at lower elevations, but at high elevations temperatures are cold enough that snow cover remains stable, except in summer. This pattern is evidently not resolved in CESM. In this context it is also interesting to note that the warming signal in spring is very similar in WRF and CESM, even though WRF has a large temperature bias in spring and employs a much simpler snow model. In fall the pattern is similar to winter, albeit with less polar amplification. These values are consistent with 


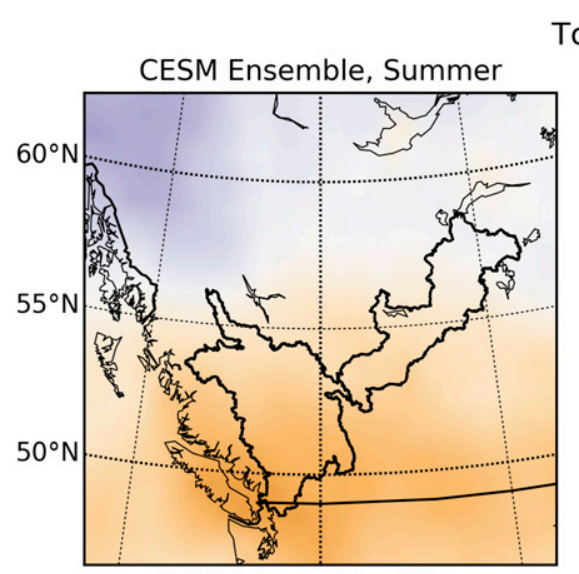

CESM Ensemble, Winter

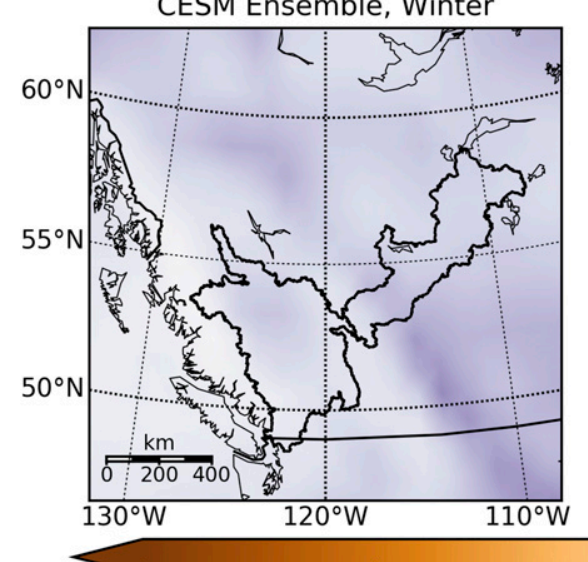

$-90$

Total Precipitation Rate Fractions [\%] 1st WRF Ens. (10km), Summer

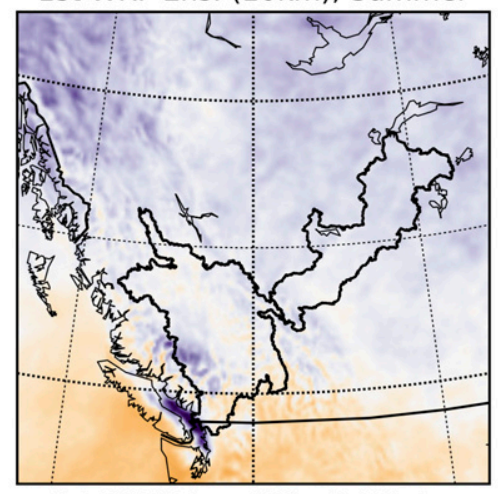

1st WRF Ens. (10km), Winter

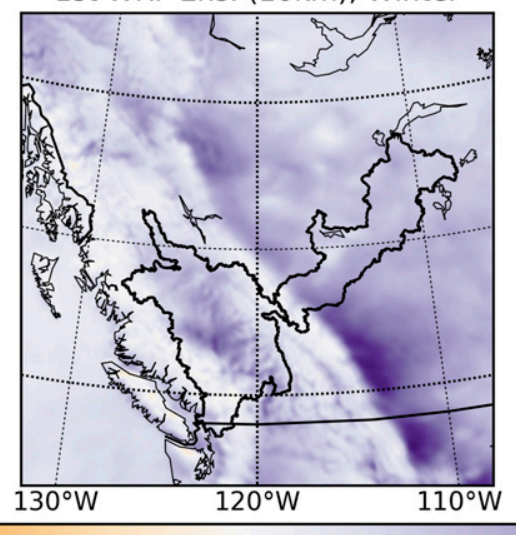

Alt. WRF Ens. (10km), Summer

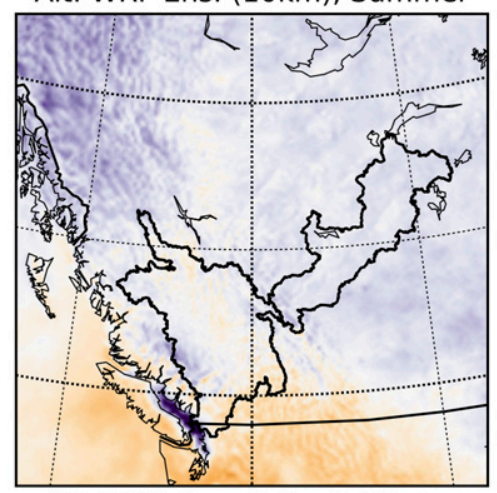

Alt. WRF Ens. (10km), Winter

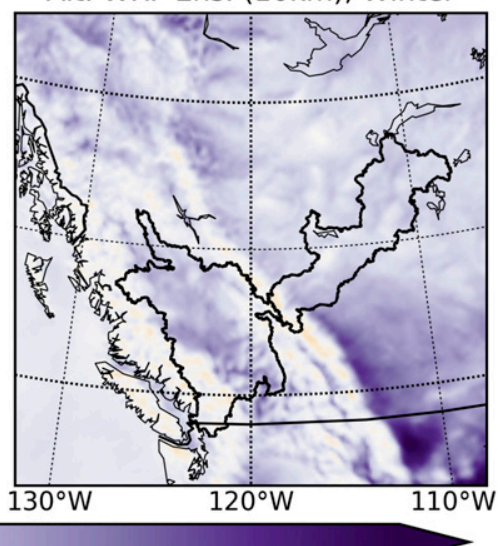

60

FIG. 5. As in Fig. 5, but for relative changes in seasonal mean precipitation.

the CMIP5 ensemble projections for this region as published in the Fifth Assessment Report (Christensen et al. 2014). Further note that, when comparing the midcentury and end-century changes in Table 1, the midcentury values are consistently very close half the end-century changes; however, the spacing of the time periods is not equal, implying that climate change is accelerating toward the end of the century.

The impact of global warming on precipitation patterns is less clear. The relative increase in total domain averaged precipitation by season is also listed in Table 1 . Both CESM and WRF show precipitation increases, but the increase is consistently larger in WRF: in the annual average, $19 \%$ and $17 \%$ in the first and alternate WRF ensemble versus $11 \%$ in CESM. Again, in winter, spring and fall CESM and WRF are more consistent with increases of the order of $20 \%$ in all models (slightly less in CESM). Furthermore, all models show the largest increase in precipitation in spring (consistently over $20 \%$ ), while at the same time all models consistently show the smallest warming signal during this season. It is possible that the increase in precipitation in spring leads to an increase in evapotranspiration and latent heat cooling, which offsets some of the warming. In summer, however, over most of the domain of interest the changes in CESM and WRF are opposite (but with the two WRF ensembles again showing consistent changes): CESM projects a decrease of $7 \%$ in summer precipitation compared to an increase of $5 \%$ and $6 \%$ in the two WRF configurations. Note, however, that there is also one WRF ensemble member in which summer precipitation decreases.

Figure 5 shows the spatial distribution of precipitation changes between the validation and the projection periods (same layout as in Fig. 4; note that relative changes are shown). It is evident that precipitation changes in summer are a strong function of latitude: CESM projects a significant decline in precipitation in large parts of the area of interest south of $55^{\circ} \mathrm{N}$; this includes most of the Fraser and Athabasca River basins. The two WRF ensembles, on the other hand, only project a decline in precipitation south of $50^{\circ} \mathrm{N}$, which does not include most of the two river basins. The decrease in 
precipitation south of the transition is of the order of $20 \%-30 \%$. A similar north-south gradient is also visible in spring, even though there is no precipitation decrease anywhere in the domain of interest. It is worth noting that the sign and regional pattern of the precipitation change in summer is not always consistent between ensemble members and the distinct north-south gradient only clearly emerges in the ensemble mean.

The precipitation increase in the cold season (fall and winter) shows a pattern that is clearly tied to topographic features, with less relative increase over mountain ranges and significantly higher relative increase in the rain shadows, especially in the lee of the Rocky Mountains. In absolute terms, however, the increase in cold season precipitation is much more uniform across the domain (approximately $0.5 \mathrm{mmday}^{-1}$ ), with the largest absolute increase at the windward side of the Coast Mountains (approximately $2 \mathrm{~mm} \mathrm{day}^{-1}$ ) and the smallest in the Canadian Prairies (approximately $0.2 \mathrm{~mm} \mathrm{day}^{-1}$ ). We further note that in some areas in the rain shadow of Vancouver Island precipitation is actually projected to decrease slightly (only in WRF), which may indicate dynamical changes.

In Figs. 2-5 only the inner domain is shown for WRF. However, while there are notable differences between the inner and the outer domain compared to observations, we find that the climate change signal for both temperature and precipitation, in all seasons, is remarkably similar in both domains. In fact, averaged over the area of the inner domain, the warming rate in the outer domain is always within at most $0.2^{\circ} \mathrm{C}$ and the precipitation change within 1 percentage point of the inner domain in all seasons.

The general pattern of change over North America in summer, with a precipitation decrease in the south and an increase in the north, as well as the location of the transition zone in CESM is consistent with the CMIP5 ensemble as reported in the AR5. Furthermore, it has already been noted that the transition zone is located farther to the south in higher-resolution models, which is consistent with the differences we find between WRF and CESM (cf. Christensen et al. 2014). The pattern of change in winter in our simulations is consistent with the CMIP5 simulations. However, we do not see a decrease of precipitation in the coastal mountain ranges in the U.S. Northwest (the state of Washington), which has been reported in Salathé et al. (2010) and Endo et al. (2012). The reason for this difference is unclear.

It has been pointed out above that the projected summertime warming in CESM is significantly larger than in WRF; this is primarily the case in the region south of the transition zone, where CESM projects a decrease in summer precipitation, but WRF does not.
This region of North America in the rain shadow of the coastal mountain ranges is characterized by a relatively dry climate, where evapotranspiration in summer is limited by moisture availability. These climates are known to be more sensitive to warming due to their limited capacity for latent heat cooling (Koster et al. 2004; Seneviratne et al. 2010). It is thus plausible that in this region the warming trend is considerably enhanced by the decrease in precipitation in the global model.

\section{Two major river basins}

In this section the impact of climate change on two major river basins in western Canada will be discussed. Figures 6 and 7 show the seasonal cycle of hydroclimatic variables averaged over the FRB and ARB. Different variables are shown in different colors (see legends). Historical model results are shown as solid lines, midcentury projections as dash-dotted lines, and projections for the end of the twenty-first century are shown as dashed lines. Historical observations are shown as filled circles. The observed values have been assembled from gridded observational products and averaged over the area of the basins (see section 2c, and section S1 in the supplemental material, for details). ${ }^{1}$ Only minimum, maximum, and mean temperatures, total precipitation, and the observed river discharge of the Fraser and Athabasca Rivers are available from observations. All variables were averaged over the entire basin area and over each 15-yr simulation period and all ensemble members. Annual means are shown in the vertical bars to the right of each panel in Figs. 6 and 7 (same line styles and colors). The error bars or bands are based on the standard error of the mean (SEM), which is defined as $\mathrm{SEM}=s / \sqrt{n}$, where $s$ is the sample standard deviation and $n$ is the sample size. The error bars/bands show a 2 SEM neighborhood, which is equivalent to a $95 \%$ confidence interval based on the Student's $t$ test. This means that if two lines lie outside of each other's error bars/bands, the difference is statistically significant, based on the Student's $t$ test with a significance level $\alpha=5 \%$. Note that while the lines only represent ensemble means, the error bands are based on the combined interannual variability of all ensemble members, where every year represents one sample (i.e., $n=4 \times 15=60$ in this case).

Figures 6 and 7 (top) describe general climatic conditions (temperature at left and precipitation at right),

\footnotetext{
${ }^{1}$ Technically, observational products are derived from point observations while model output represents averages across grid cells. However, Eggert et al. (2015) show that this is only a concern for short-term (subdaily) extremes.
} 
Fraser River Basin, Projection

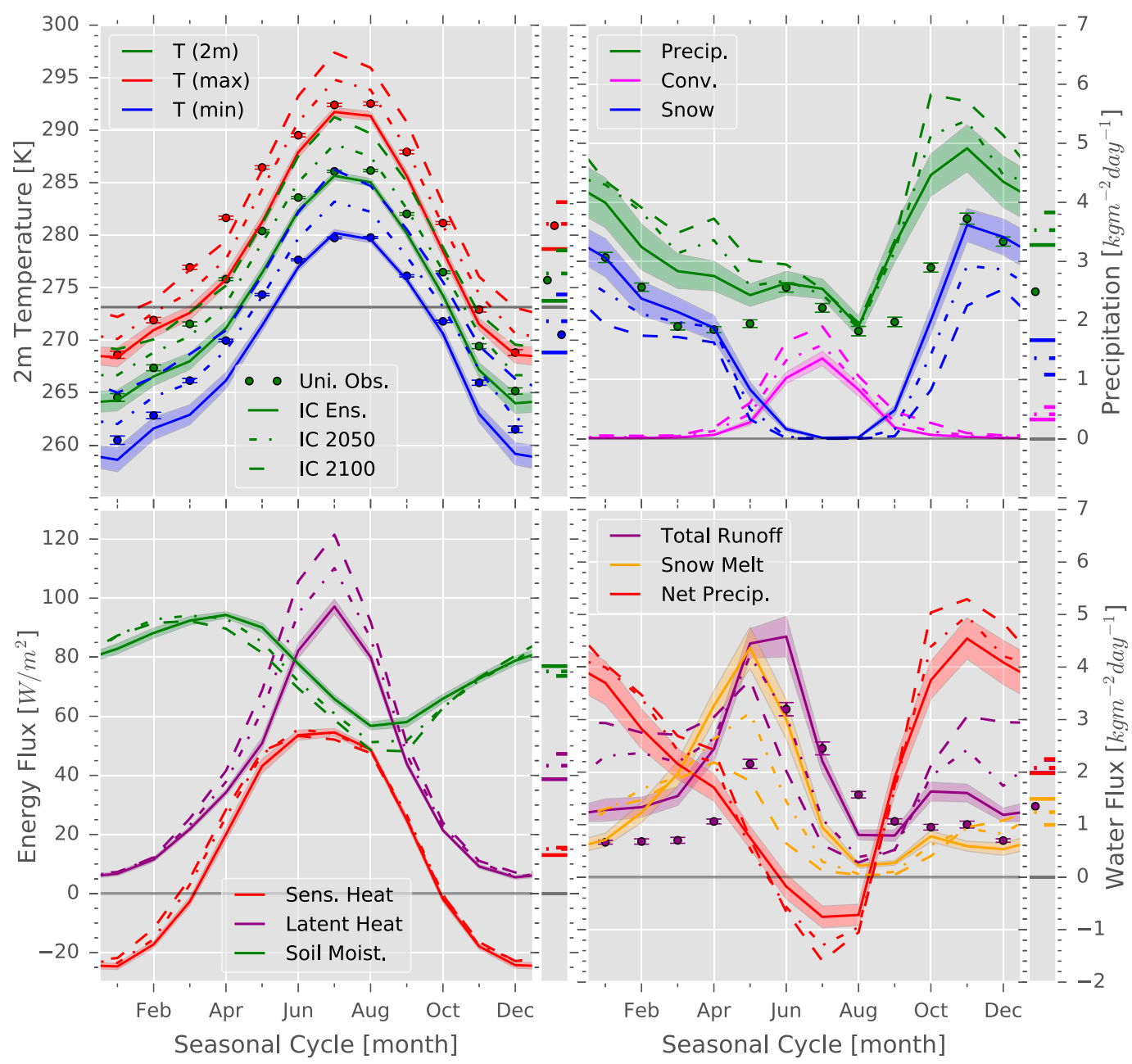

FIG. 6. Average seasonal cycle over the Fraser River basin: (top left) average, minimum, and maximum 2-m air temperature; (top right) total, convective, and solid precipitation; (bottom left) latent and sensible heat flux and relative soil moisture; and (bottom right) total runoff, net precipitation and snowmelt, and Fraser River discharge. All quantities are averaged over the entire basin; river discharge was normalized by the basin area. The $y$-axis range for relative soil moisture is $0 \%-100 \%$ (no labels). The historical validation period is shown in solid lines, mid- and end-of-twenty-first-century projection periods are shown by dash-dotted and dashed lines, respectively; observed values are indicated with filled circles. Error bars/bands show the standard error of the mean at a $95 \%$ confidence level. Only the first WRF ensemble is shown; an equivalent figure with results from the alternate WRF ensemble is shown in Fig. S4.

while Figs. 6 and 7 (bottom) are intended to characterize hydrological impacts (soil moisture at left and runoff at right). The minimum and maximum temperatures (Figs. 6 and 7, top left) are daily minima and maxima of 2-m air temperature (i.e., the diurnal range). Solid precipitation is snow and graupel; convective precipitation is the amount of precipitation that is generated by the cumulus scheme alone (Figs. 6 and 7, top right); net precipitation (Figs. 6 and 7, bottom right) is defined as total precipitation minus actual evapotranspiration (ET). Note that surface heat fluxes, ET, soil moisture
(Figs. 6 and 7, bottom left), snowfall (Figs. 6 and 7, top right), and snowmelt and runoff (Figs. 6 and 7, bottom right) are computed by the Noah land surface model (total runoff is the sum of surface and underground runoff). The Noah LSM is a simple column model with a 2-m soil layer that operates on a point-by-point basis on the same grid as WRF. Therefore, horizontal fluxes such as river routing and groundwater flow are not accounted for, and timing differences are expected when comparing LSM runoff to actual river hydrographs. Observed river discharge was converted 


\section{Athabasca River Basin, Projection}

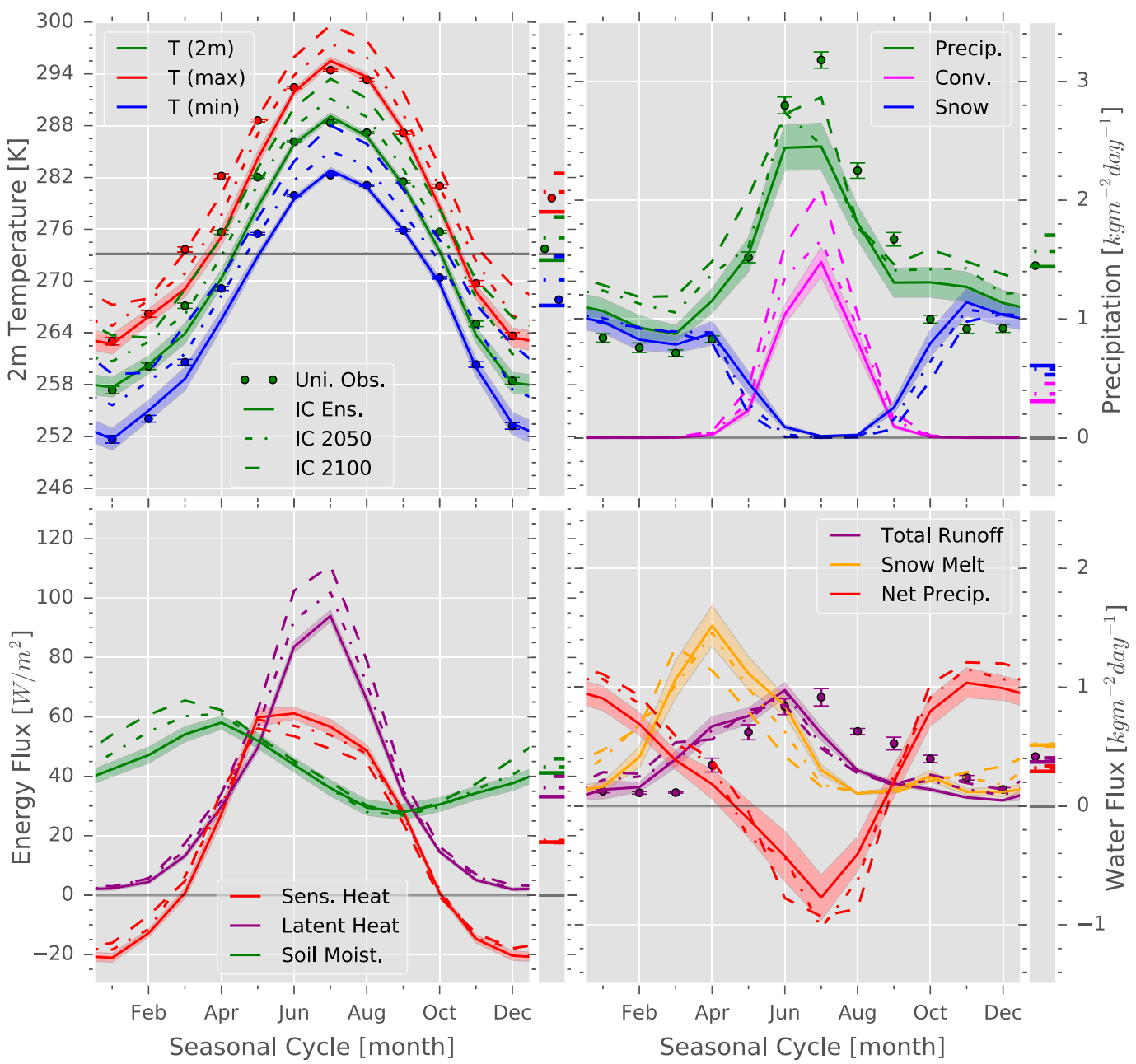

FIG. 7. As in Fig. 6, but over the Athabasca River basin. Note however, that the $y$-axis scaling is different. An equivalent figure with results from the alternate WRF ensemble is shown in Fig. S5.

into average runoff by dividing by the drainage area associated with the gauging station (see section S1.2 in the supplemental material for details on the selected stations).

The idealized study of Das et al. (2011) can serve as a guide for the interpretation of hydrological changes based on changes in the climate. To briefly summarize their results, warming is expected to causes a shift from solid to liquid precipitation and earlier (and less) snowmelt, which increases streamflow in winter but reduces streamflow in summer; furthermore, warming is also expected to increases evapotranspiration, which can significantly reduce streamflow in summer but is less important in winter.

Figures 6 and 7 only show basin-averaged results for the first WRF ensemble; results for the alternate ensemble are shown in Figs. S4 and S5 in section S3 of the supplemental material; the first WRF ensemble was chosen over the alternate ensemble because it shows better overall the agreement with observations and does not have a significant radiation bias.

\section{a. The Fraser River basin}

The Fraser River originates in the Rocky Mountains and runs westward across the Interior Plateau and eventually drains into the Pacific Ocean near the city of Vancouver. The Fraser River basin is located westward of the Rocky Mountains and the Continental Divide, but much of it is within the rain shadow of the Coast Mountains. Note that the Pacific seaboard (mostly the western slopes of the Coast Mountains), which receives most of the orographic precipitation, is not part of the FRB.

Figure 6 describes the seasonal cycle of hydroclimatic variables over the FRB, based on the first WRF 
ensemble; the data from the alternate WRF ensemble is shown in Fig. S4. It is evident that temperatures are generally too cold (by $2.8^{\circ} \mathrm{C}$; Fig. 6 , top left) and precipitation is too high (by $18 \%$; primarily in winter; Fig. 6 , top right) compared to observations. The seasonal cycle in temperature is quite well reproduced, except for an even larger cold bias in spring, which is likely associated with the snow model (as discussed in section 3a). The seasonal cycle in precipitation is too strong, owing largely to excessive winter precipitation (the wettest season), whereas summer precipitation is simulated quite well. The winter precipitation bias can partly be explained by an underestimation of the rain shadow effect (cf. section 3a). As discussed in Erler et al. (2015), the precipitation deficit over the relevant section of the Pacific seaboard (Vancouver Island and the Coast Mountains) can account for approximately $50 \%$ of the excess precipitation over the FRB (see section S3.3 in the supplemental material for a discussion of climate change in the Pacific Seaboard). Furthermore we note that the station density in parts of the FRB and the Coast Mountains is very low, so that the observational error can also be large (the density of stations used in the GPCC gridded precipitation dataset is shown in Fig. S1 of the supplemental material). Similar results for the alternate WRF ensemble are shown in Fig. S4. The temperature bias, especially in summer, is significantly smaller in the alternate WRF ensemble (likely due to excessive solar radiation); the precipitation bias is greater even across the year, resulting in a better representation of the seasonal cycle but a similar overestimation in the annual mean due to a much larger bias in summer (about 30\%; cf. Fig. S4, top right).

The partitioning between liquid and solid precipitation during the winter is fairly even (Fig. 6, top right) and there is, unsurprisingly, virtually no solid precipitation in summer. Also as expected, convective precipitation peaks in summer and is insignificant in winter; it is interesting to note that convective precipitation is significantly larger in the alternate WRF ensemble; the difference in convective precipitation essentially explains the difference in total summer precipitation. The role of (the fraction of) convective precipitation in changes in precipitation extremes is discussed in detail in Erler and Peltier (2016). During summer evapotranspiration exceeds precipitation, and the basin experiences a net water loss (cf. net precipitation; Fig. 6, bottom right). Interestingly, the amount of net precipitation is almost identical in the two WRF ensembles due to a compensation between higher summer precipitation and higher evapotranspiration in the alternate ensemble (Fig. S4, bottom right). Runoff during the historical period clearly follows the timing of snowmelt in spring, at least in the Noah land surface model. Compared to the observed river discharge, the timing of the runoff peak is about one month earlier in the model. At least some contribution to the earlier timing can be accounted for by river routing delay and storage; another factor could be later snowmelt at higher elevations that are not resolved even in the 10-km WRF topography.

Relative soil moisture as well as latent and sensible heat fluxes are also shown in Fig. 6 (bottom left). Even though observational data are not available to validate the historical observations, we nevertheless point out that a significant discrepancy exists between the two WRF ensembles in latent and sensible heat fluxes: both fluxes, but in particular the latent heat flux (i.e., evapotranspiration), are significantly larger in the alternate ensemble than in the first WRF ensemble; this is likely caused by the significant radiative forcing bias in the alternate WRF ensemble.

To determine which of the two WRF configurations has the more realistic evapotranspiration (latent heat flux), we can invoke a water and energy balance argument. The amount of annual average ET from the FRB can be estimated by subtracting the annual mean of the Fraser River discharge normalized by the drainage area from the annual average precipitation rate over the basin. This yields an equivalent of approximately $1.15 \mathrm{~mm}$ day $^{-1}$; the corresponding ET values in the two WRF ensembles are 1.25 and $1.5 \mathrm{~mm} \mathrm{day}^{-1}$, respectively. The ET rate in the alternate WRF ensemble is clearly too high compared to the observed water budget. This is consistent with previously identified radiation bias in the alternate WRF configuration, because otherwise a significant warm bias would be expected, in particular in summer. This is clearly not the case in the Fraser River basin; however, it appears to be the case to the east of the continental divide (in the alternate WRF ensemble). Whether or not the ET bias (because of excess precipitation) in the first ensemble can explain the cold bias over the FRB in summer is not clear, but it appears plausible (possibly with a contribution from the delayed snowmelt in spring). This energy balance argument suggests that the relatively accurate temperatures in the alternate ensemble could be a consequence of compensating errors, while the cold bias in the first WRF ensemble may be a consequence of the large precipitation bias. As a consequence, soil moisture is also somewhat lower in the alternate ensemble.

The mean temperature in the $\mathrm{FRB}$ is projected to increase by $4.9^{\circ} \mathrm{C}\left(2.6^{\circ} \mathrm{C}\right.$ by midcentury), and annual precipitation by $21.5 \%(7.5 \%)$; the changes in the alternate WRF ensemble are essentially the same, including almost no change in summer precipitation. Note, 
however, that because of the high degree of natural variability, precipitation changes at midcentury are only significant in fall and spring, but not in winter, whereas the temperature-induced change from solid to liquid precipitation and in particular the decline in spring snowmelt are very robust (as evidenced by the $95 \%$ confidence intervals in Fig. 6). These changes cause a substantial change in the seasonal cycle of runoff from a snowmelt-driven peak in spring to a regime with a strong decrease in runoff in late summer, but much more even distribution during the rest of the year. The implications for flood and drought risk are potentially profound and will be discussed further in section $5 \mathrm{c}$. The reduction in peak snowmelt by the end of the century is approximately 50\%! Again, the climate change response is essentially the same in the alternate WRF ensemble, including the dramatic reduction in snowmelt.

The significant changes to the hydrological cycle of the FRB seen in our simulations are consistent with the findings of previous studies (Salathé et al. 2010; Shrestha et al. 2012; Pollock and Bush 2013). In particular, all of the major changes are already apparent during the midcentury projection period, as discussed by Erler et al. (2015). The only major difference compared to previous work is that we do not find evidence for strong drought conditions in late summer, as reported by Shrestha et al. (2012). Even though relative soil moisture does decrease by a statistically significant amount in our projections, latent heat fluxes (i.e., ET) consistently increase, while sensible heat fluxes remain unchanged (the Bowen ratio increases). If ET was limited by soil moisture content, the reverse would be expected (Dai 2011). This behavior is the same in the WRF alternate ensemble. We will return to the problem of drought risk in section $5 \mathrm{~b}$.

The results presented here are based on a primarily atmospheric model with only a simple column-land surface model, without river routing or subsurface hydrology. Nevertheless, we are able to infer likely changes in streamflow based on the idealized simulations of Das et al. (2011) and the climatic drivers discussed above. The climate change impacts identified by Erler et al. (2015) for midcentury essentially remain valid for the end-of-century projection period and the alternate WRF ensemble: significantly reduced streamflow in late summer and spring and significantly increased streamflow during fall and winter.

\section{b. The Athabasca River basin}

Like the Fraser River, the Athabasca River originates in the Columbia ice field in the Rocky Mountains. However, unlike the Fraser River, the Athabasca River runs to the northeast and eventually drains into the Arctic Ocean (although the Athabasca River ends at
Lake Athabasca). The ARB is thus located on the eastward side of the continental divide.

The seasonal cycle of hydroclimatic variables from the first WRF ensemble for the ARB is shown in Fig. 7; the data from the alternate WRF ensemble are shown in Fig. S5. Except in spring, the seasonal cycle and the diurnal range of temperature (Fig. S5, top left) are evidently very accurately reproduced in the first WRF ensemble. However, the annual temperature bias in the first WRF ensemble is still $-1.4^{\circ} \mathrm{C}$, resulting from the already discussed cold bias in spring. The annual temperature bias is significantly smaller in the alternate ensemble; this is, however, due to a compensation between a similarly large cold bias in spring and the already mentioned warm bias in summer (cf. Fig. 2), which is likely caused by too little cloud cover. Unlike the FRB, precipitation in the ARB peaks in summer and is relatively low in winter (Fig. 7, top right); qualitatively the seasonal cycle is well captured in WRF, but the contrast between summer and winter is still underestimated. In both WRF ensembles the annual mean is very close to observations, but the seasonal contrast is somewhat better represented in the alternate WRF ensemble than in the first WRF ensemble. The outer WRF domains as well as CESM are characterized by a progressively weaker seasonal cycle, with more precipitation in winter and less in summer (not shown). We therefore speculate that the higher winter precipitation is again likely due to an underestimation of the rain shadow effect (as discussed above); however, there also appears to be a contribution from excessive drizzle during the cold season, especially in the first WRF ensemble. Again, we note that the station density in the ARB is relatively low (cf. Fig. S1), so that the observational error can be large as well. In summer a large fraction of total precipitation occurs as convective precipitation, and, as in the FRB, this component is significantly larger in the alternate WRF ensemble. Consistent with the findings of Erler and Peltier (2016) for the Canadian Prairies, the fraction of convective precipitation in summer is about $50 \%$ in the first WRF ensemble (using the Grell 3D cumulus scheme) and above $70 \%$ in CESM and the alternate WRF ensemble (the latter employing the KainFritsch scheme).

Because of the colder continental climate, winter precipitation in the ARB primarily occurs as snow, which leads to a snowmelt-driven runoff peak in spring (Fig. 7, bottom right). Even though the precipitation maximum in the ARB occurs in summer, most of the water evaporates so that net precipitation in summer is actually negative (Fig. 7, bottom). This leads to a minimum in relative soil moisture in summer due to higher evapotranspiration and a maximum in spring following 
the thawing of the winter snowpack. We note that the Bowen ratio (latent over sensible heat flux) keeps increasing throughout the summer and actual ET follows the seasonal cycle of potential evapotranspiration (PET), indicating that ET is not limited by soil moisture availability. This is also the case in the alternate WRF ensemble, but as a result of the stronger radiative forcing, evaporation is higher, leading to somewhat lower soil moisture and runoff (year-round).

The observed peak streamflow in the Athabasca River occurs in July, and flow levels remain relatively high until late fall (cf. Fig. 7, bottom right). The snowmelt (and surface runoff) peak in our simulations appears about three months before the observed peak river discharge. The total runoff peak in the simulations occurs about two months later, but still one month before but the observed peak, and the water supply is not maintained throughout the summer. This delay may be too long to be explained simply by routing delay. Later snowmelt at higher elevations may be one reason, but Kerkhoven and Gan (2011) also note that up to $70 \%$ of the runoff at lower elevations may occur in the form of (horizontal) interflow through peat or muskeg. This flow component is not represented in the Noah LSM, and it could potentially delay the annual peak flow significantly and retain water until much later in the year. Ultimately, detailed surface and subsurface hydrologic modeling will be required to faithfully model streamflow in the ARB. The mismatch in runoff timing compared to observed streamflow is similar in both WRF configurations; the error in total annual runoff compared to streamflow is about $10 \%$ in the first WRF ensemble but $20 \%$ in the alternate ensemble as a result of higher evapotranspiration (which is likely caused by the radiation bias).

The projected warming in the $\mathrm{ARB}$ by the end of the twenty-first century is $4.2^{\circ} \mathrm{C}\left(2.5^{\circ} \mathrm{C}\right.$ by midcentury $)$ in the first WRF ensemble and $4.5^{\circ} \mathrm{C}\left(2.7^{\circ} \mathrm{C}\right)$ in the alternate WRF ensemble. The projected annual precipitation changes are $21 \%(10 \%)$ in the first and $17 \%(8 \%)$ in the alternate WRF ensemble; by the end of the century both WRF ensembles show a statistically significant increase in precipitation in all seasons except late summer-early fall. In both WRF ensembles a large component of the change could be described as a shift of the summer precipitation peak earlier into the year (by about one month); however, this shift appears to be more pronounced in the alternate WRF ensemble. Furthermore, convective precipitation is projected to increase significantly in both WRF ensembles, and can account for the entire increase in summer precipitation. As in the FRB, because of high interannual variability, precipitation changes for the midcentury period are often not statistically significant and inconsistencies between the two WRF ensembles appear relatively more pronounced.

Because of the continental climate of the ARB, winter temperatures are considerably lower so that the partitioning between solid and liquid precipitation in winter does not change appreciably, and changes in the phase of precipitation are confined to fall and spring. In fact, because of the increase in total precipitation, the change in the total amount of snow is only small: about $10 \%$ at the end of the twenty-first century, and statistically not significant at midcentury. A major change in the basin hydrology is the shift in the timing of snowmelt: the snowmelt peak is projected to occur about one month earlier and at a somewhat lower level than during the historical period. It is possible that this is also the reason for the earlier onset of summer precipitation.

Interestingly, the shift in the snowmelt peak does not appear to translate into significant changes in (total) runoff; in fact changes in runoff are hardly significant in spring and summer and the same is true for relative soil moisture changes. Evidently the earlier snowmelt and increased ET are compensated for by the increase in spring and summer precipitation. The only significant changes in soil moisture occur in the cold season and are positive (presumably due to higher infiltration of liquid precipitation). It is further evident that latent heat fluxes increase more than sensible heat fluxes, indicating that soil moisture is not limiting evaporation (on average). In fact, the sensible heat flux decreases slightly in summer, which indicates increased moisture availability. This revises the earlier conclusions of Erler et al. (2015), who anticipated an increased drought risk in the ARB, based on a slight drying tendency in the ARB at midcentury (which is statistically not significant).

It is not clear to which extend the changes (or lack thereof) in total runoff from the Noah LSM can give a meaningful indication of future streamflow changes. Based on the arguments of Das et al. (2011), it does seem likely that cold season streamflow will increase somewhat (consistent with WRF runoff changes). Whether summer streamflow will increase or decrease, given the competing effects of earlier snowmelt and warmer temperatures on one hand and increasing summer precipitation on the other, is less clear. We conclude that, based on the two WRF ensembles, it is likely that changes in either direction will be small. This is contrary to previous findings, which were based on CMIP3 or CMIP5 GCM simulations (Kerkhoven and Gan 2011; Leong and Donner 2015), and also contrary to recent observed trends (Sauchyn et al. 2015). The disagreement with GCM-based studies is, however, not unexpected: the ARB is located close to 


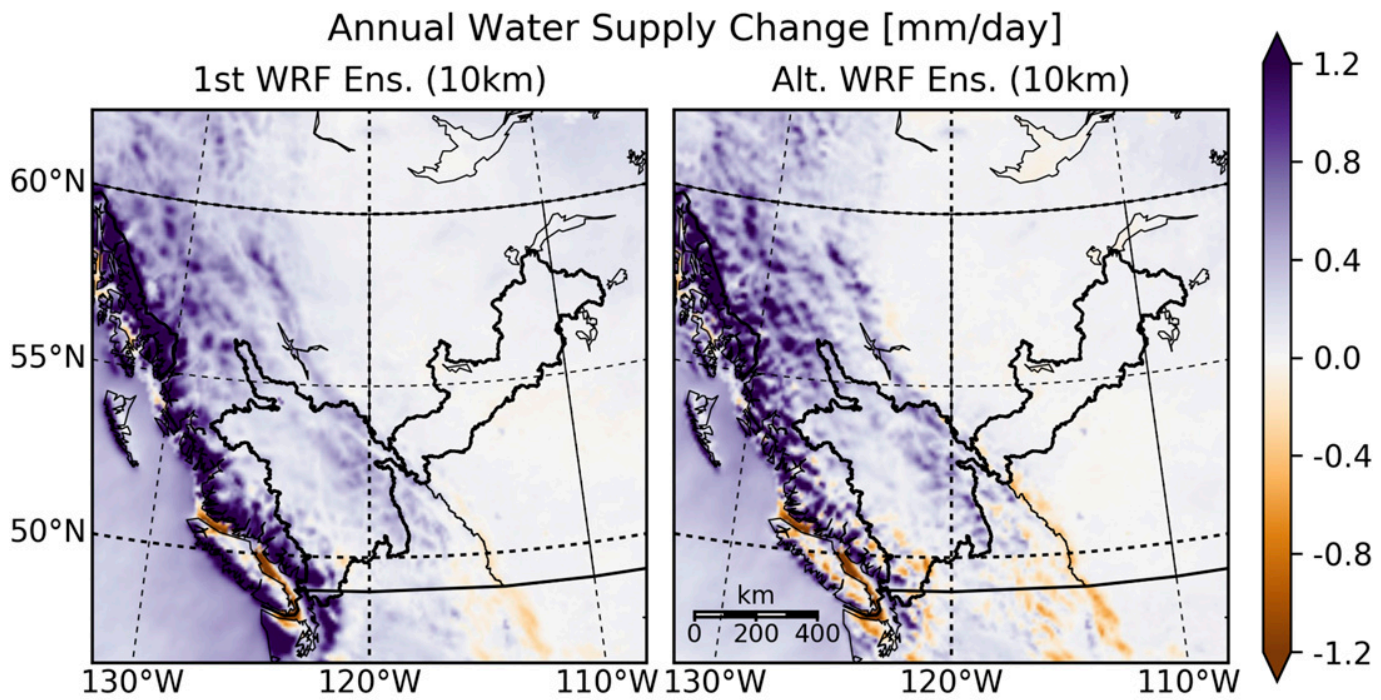

(absolute) Soil Moisture Fractions [\%]

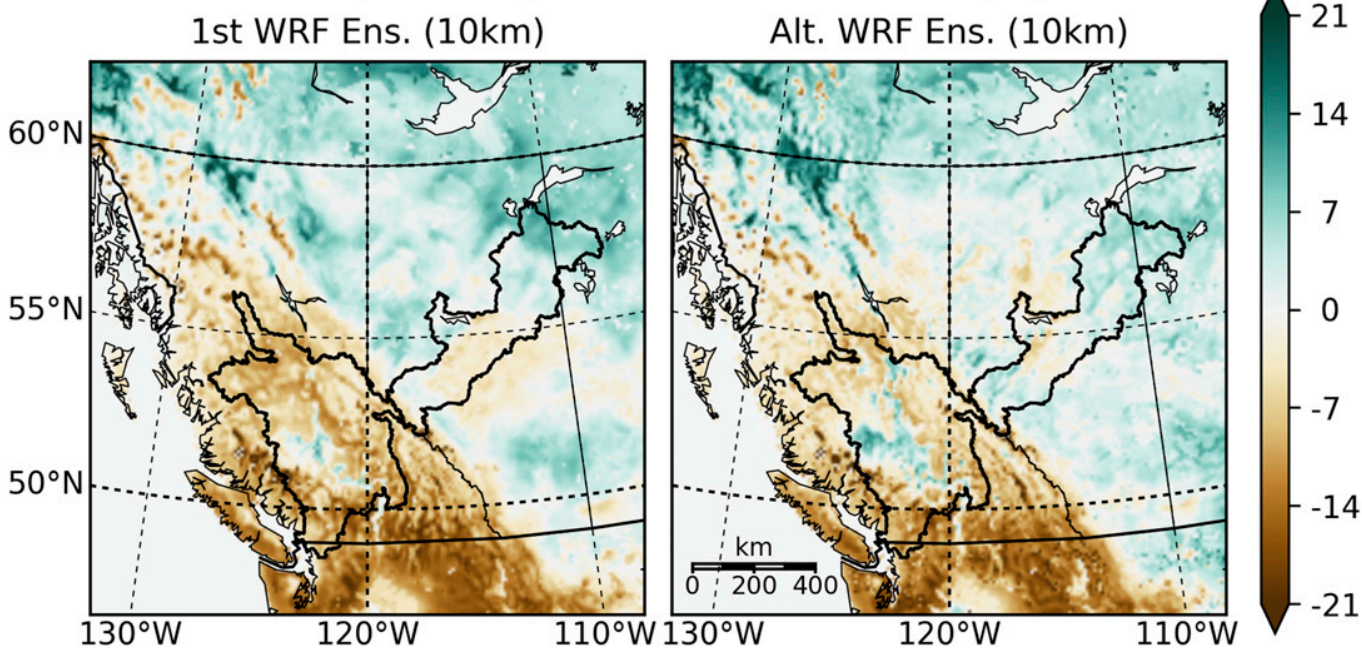

FIG. 8. Geographic distribution of (top) absolute changes in annual average water supply (net precipitation) and (bottom) relative changes in late summer absolute soil moisture by the end of the twenty-first century for the (left) first and (right) alternate WRF ensemble. The outlines of the FRB and the ARB are shown, as well those of the Canadian provinces of British Columbia, Alberta, and Saskatchewan. Note that the border between BC and Alberta follows the continental water divide from $49^{\circ} \mathrm{N}$ up to about $54^{\circ} \mathrm{N}$.

the transition zone where CMIP3 and CMIP5 GCMs project a change from precipitation increase to decrease in summer, whereas both WRF ensembles, consistent with other high-resolution AGCMs and RCMs, place the transition line firmly to the south of the ARB, thus projecting a precipitation increase in summer.

\section{Water supply and hydroclimatic extremes}

The goal of this section is to document the interannual variability in water supply to the Fraser and Athabasca
River basins, as well as to provide a preliminary estimate of changes in future flood and drought risk, based on the climate projections presented here.

\section{a. Annual water supply projections}

One of the most important concerns with regard to climate change in the PNW is its impact on water resources. Here we attempt to estimate changes in total annual water supply, as well as the interannual variability of water supply.

Figure 8 (top) shows the spatial distribution of absolute changes in annual and ensemble mean net 


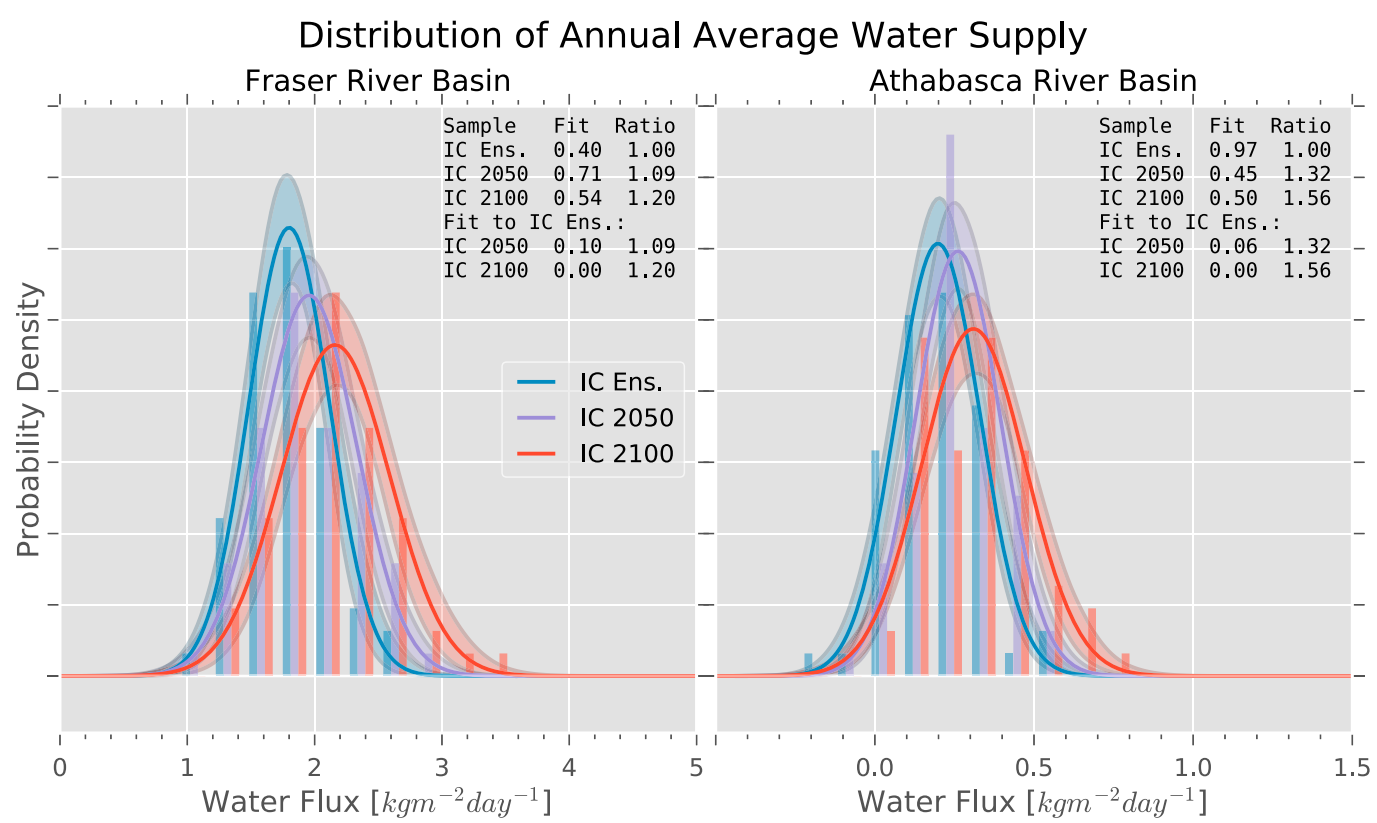

(absolute) Soil Moisture Distribution (JAS-Mean)

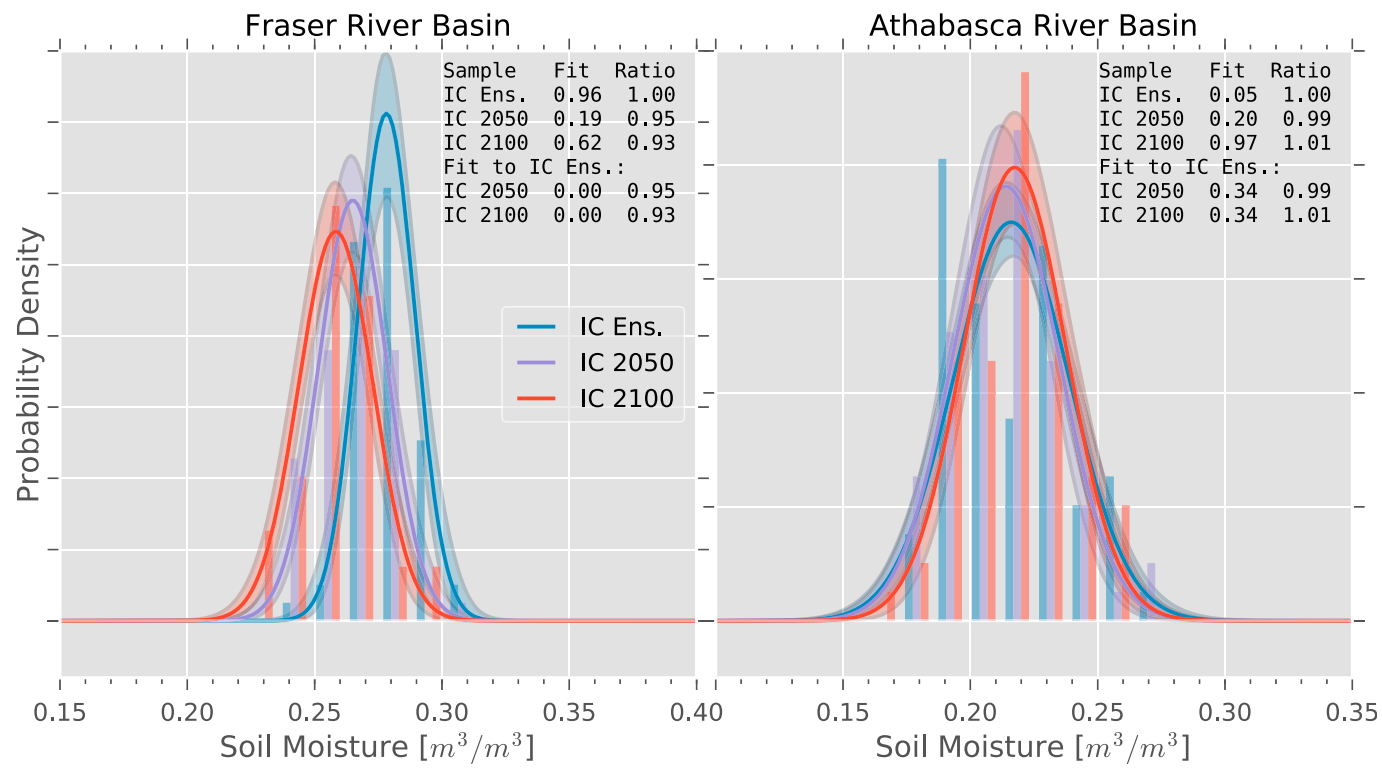

FIG. 9. Distribution of (top) total annual average water supply and (bottom) late summer (July-September) soil moisture for the (left) Fraser and (right) Athabasca River basins. The semitransparent bands are $80 \%$ confidence intervals, derived from bootstrapping. Each data point represents one year, resulting in a sample size of 60 for each ensemble. Only the first WRF ensemble is shown; an equivalent figure with results from the alternate WRF ensemble is shown in Fig. S7.

precipitation (precipitation minus evapotranspiration) for the first and the alternate WRF ensemble (Fig. 8, left and right, respectively); note that absolute changes (in $\mathrm{mm} \mathrm{day}^{-1}$ ) are shown, rather than relative changes. It is evident that for most of western Canada an increase in annual water supply is projected. The increase is especially pronounced in areas that already receive higher amounts of precipitation, such as the Canadian Cordillera, the Coast Mountains, and to a lesser extent the Rocky Mountains. A noticeable decrease is only projected in the U.S. part of the Rocky Mountains. Essentially no changes in water supply are projected for the more arid regions of the domain, such as the Interior Plateau and the Canadian Prairies. The reason is that the 
increase in evaporative demand is largely compensated by an increase in precipitation. The alternate WRF ensemble shows a slightly larger tendency toward reduced water availability in the southeast of the domain; however, evapotranspiration in the alternate WRF configuration is likely overestimated as a result of the radiative forcing bias discussed in sections $3 \mathrm{a}$ and 4.

A particularly relevant quantity for water resource management is the total water supply integrated over a basin (net basin supply). In the annual average, total water supply is equivalent to net precipitation (assuming the seasonal snowpack melts completely each summer). Histograms of annual average water supply averaged over each basin are shown in Fig. 9 (top; FRB at left and ARB at right) for all three periods. Only the first WRF ensemble is shown; for the alternate WRF ensemble an equivalent figure is shown in Fig. S7 of the supplemental material. Note that each sample is comprised of one value per year and per ensemble member. Utilizing all four ensemble members yields a sample size of $n=4 \times$ $15=60$ for each of the two WRF ensembles (as in section 4). A Normal distribution was fitted to the samples from each period (solid lines); however, because each fit is constrained by only 60 values, sampling uncertainty is relatively high. The range of sampling uncertainty is shown by means of $80 \%$ confidence intervals (semitransparent bands), based on the bootstrapping method (Efron and Tibshirani 1994). A normal distribution was chosen for the fit, because samples are simple spatial and temporal averages. ${ }^{2}$ The quality of fit for each set of samples, as measured by the $p$ value from on the ShapiroWilk test (von Storch and Zwiers 2002; Steinskog et al. 2007), is shown in each panel of Fig. 9 ("Fit" heading), followed by the ratio of the sample mean to the historical sample mean ("Ratio" heading). The quality of fit in all cases is acceptable, given the small number of samples. In the discussion of climate change impacts, a critical distinction is that between natural variability and changes forced by the increase of greenhouse gases. For this reason we also employ the Shapiro-Wilk test to test the null hypothesis that the samples from the projection periods were drawn from the same parent distribution as the historical samples. The $p$ values for this hypothesis test are also shown in each panel of Fig. 9 (under the "Fit to..." heading). It is evident that the changes in the interannual distribution of basin-integrated water supply are highly significant by the end of the twenty-first century, but indistinguishable from natural variability

\footnotetext{
${ }^{2}$ According to the central limit theorem, the normal distribution is the limit distribution of a large number of averages of any type of distribution (von Storch and Zwiers 2002).
}

during the midcentury period. In the FRB the increase in water supply by the end of the century is about $20 \%$, whereas in the ARB it is over $50 \%$. Note, however, that the net water supply to the ARB is very small compared to that of the FRB, and in absolute terms the increase in the FRB is larger than in the ARB (even when normalized by area). It is also evident that the distribution widens considerably in both basins. Further note that in the ARB some years have a negative net water balance, but the risk of that occurring is projected to decrease considerable. The distribution of basin-integrated water supply for the alternate WRF ensemble is shown in Fig. S7 (top); the results are essentially the same, except that the alternate WRF ensemble does not project an increase in variability for the end-of-century period in the ARB.

\section{b. Drought risk projections}

To estimate the risk of drought, we consider changes in late summer soil moisture. Cook et al. (2015) have demonstrated that soil moisture anomalies in climate models are roughly equivalent to the Palmer drought severity index as a measure of drought.

Changes in average late summer soil moisture in the two WRF ensembles by end of century are shown in Fig. 8 (bottom). Note that these are relative changes in absolute soil moisture, where each grid point has been averaged over July, August, and September and over the entire depth of the Noah LSM soil column ( $2 \mathrm{~m})$, as well as all ensemble members of each WRF ensembles. The spatial pattern of soil moisture change in late summer is relatively simple, but perhaps somewhat unexpected: a decrease of $10 \%-15 \%$ west of the continental divide and an increase of $5 \%-10 \%$ east of the divide by the end of the century. In winter, soil moisture generally increases $(10 \%-20 \%$ east of the Rockies and $0 \%-5 \%$ in the west; not shown), probably due to a combination of higher liquid precipitation and higher infiltration rate. The pattern appears robustly in both WRF ensembles and there are only few deviations from this pattern (e.g., in the Interior Plateau and parts of the Canadian Prairies). The reason for the increase in late summer soil moisture to the east of the continental divide is likely a compensation between increasing evapotranspiration and precipitation, combined with higher soil moisture in early summer and spring due to higher winter and spring precipitation. The decrease in late summer soil moisture west of the continental divide is likely due to increased runoff during the cold season and increased evapotranspiration in summer, combined with little change in summer precipitation. This pattern of change is quite different from the changes in annual water supply (net precipitation), but it is consistent with the changes in 
basin-integrated (relative) soil moisture discussed in section 4.

Histograms of seasonally averaged (July-September) absolute soil moisture integrated over the Fraser and Athabasca River basins, as well as normal distributions fitted to the samples for each period are shown in Fig. 9 (bottom; first WRF ensemble only). As with the water supply samples, each data point corresponds to one year (or season), making a total of $n=4 \times 15=60$ data points per WRF ensemble and for each period. The quality of fit was again assessed using the Shapiro-Wilk test, as described in section 5a. However, because the quality of fit is not as good as with annual water supply (net precipitation), we choose the nonparametric Kolmogorov-Smirnov test (K-S test; Smirnov 1939; Steinskog et al. 2007) to evaluate the significance of changes in the distribution by mid and end-century. Note that in particular with the alternate ensemble in the ARB the deviation from normality is very significant (see Fig. S7, bottom right): the distribution is clearly skewed with a longer tail toward the wetter end and what almost appears to be a cutoff at the drier end $\left(0.15 \mathrm{~m}^{3} \mathrm{~m}^{-3}\right)$. This may be indicative of nonlinear behavior where soil moisture availability severely limits evapotranspiration. We also point out that drought conditions can persist over several years (Overpeck 2013), so that annual or seasonal averages may not be entirely independent and clustering can occur in smaller samples. This is also the reason that a seasonal time scale was chosen for this analysis, rather than a monthly time scale.

It is evident that there is a significant decrease in average soil moisture in the FRB, as well as a broadening of the distribution. The changes are highly significant statistically despite the small sample size. At the same time, changes in the ARB are very small and statistically not significant. The ARB does, however, on average remain drier than the FRB. The changes are slightly smaller in the alternate WRF ensemble, but the same conclusions still hold (Fig. S7, bottom).

The soil moisture shown in Fig. 9 (bottom) is an average over all soil layers, from the surface to 2-m depth. It is interesting to note that in the FRB the largest change in fact occurs in the deepest soil layer (1-2 m). The upper soil layers $(0-0.3 \mathrm{~m})$ already become relatively dry in late summer during the historical period, while the deeper layers retain much more moisture; at the end of the twenty-first century, however, the deepest layer becomes almost as dry as the surface layer. The reason for this is presumably the strong reduction and the earlier date of snowmelt, which supplies less water in spring and effectively extends the period over which a the net water deficit is experienced. In late spring
(April-June) the opposite is the case: average soil moisture is also decreasing, but it is now driven by a substantial decrease in the upper surface layer, while there is no significant change in the lowest soil layer. But again this is only the case in the FRB; in the ARB soil moisture does not change significantly.

However, we point out that precipitation in the cold season is overestimated in both WRF ensembles, so that the water supply in our simulations may be higher than it would actually be, and soil moisture limitation may be or may become more significant than in the simulations presented here. In this light, we cannot rule out an increased risk of drought in the FRB. Decreased availability of water in late summer could have considerable implications for the logging industry as well as increase the risk of forest fires. Furthermore, agricultural producers in the southern parts of the basin, some of which already rely on irrigation at present, should be prepared for increased irrigation demands in the future. We also note that the projections of Shrestha et al. (2012), which are based on a hydrologic model forced with biascorrected GCM projections, indicate considerable drying for the FRB.

\section{c. Flood risk projections}

To study changes in the risk of major large-scale flooding events (as opposed to flash flooding), we compute the total water forcing (water flux) at the surface; it is defined as snowmelt plus liquid precipitation minus evapotranspiration. The surface water flux is then averaged monthly and over each basin, before the annual maxima are selected, to produce a time series of annual peaks of monthly water forcing. Again, combining annual values from all ensemble members of each initialcondition ensemble and period makes a total of $n=4 \times$ $15=60$ data points for each sample. A Gumbel distribution was then fitted to the samples for each time period. The Gumbel distribution is equivalent to a generalized extreme value (GEV) distribution with a fixed shape parameter of zero (Katz et al. 2002). We choose the Gumbel distribution over the GEV distribution; because the sample size is relatively small (60 samples per year), the quality of fit is as good as for the GEV distribution (as indicated by the K-S test; Smirnov 1948), and the GEV fit does not converge for all bootstrapping samples. Clearly a longer time series would be desirable. Note that this analysis is essentially an extreme value analysis; see Erler and Peltier (2016, and references therein) for a more comprehensive description of the methodology and application to precipitation extremes in western Canada.

Histograms and fitted distributions for the annual maximum water flux are displayed in Fig. 10 (top), 
Annual Maximum Monthly Water Forcing (Gumbel-Distribution)

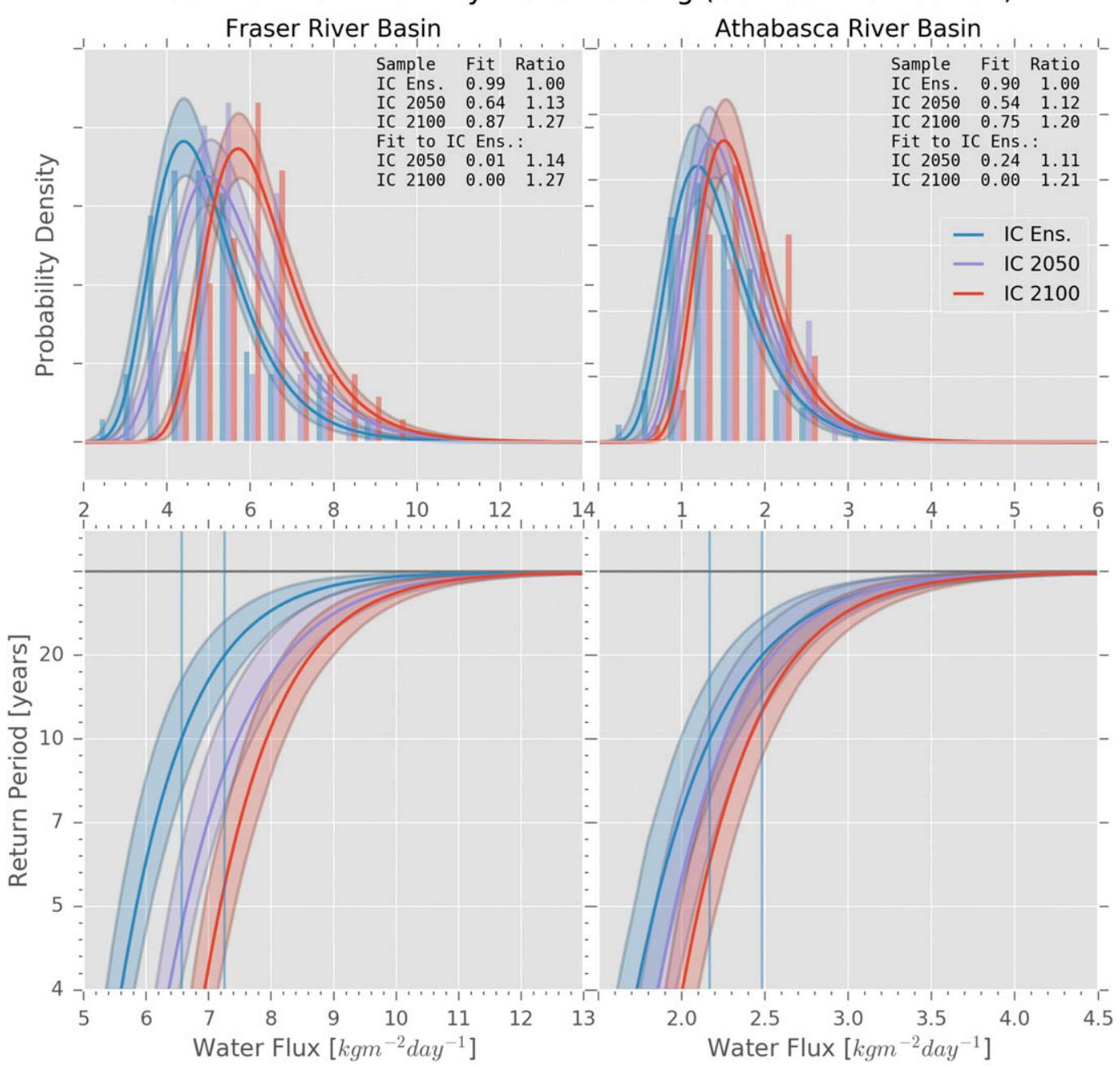

FIG. 10. (top) Distribution of annual maxima of monthly mean water forcing and (bottom) the return period for extreme quantiles of the distribution for the (left) Fraser and (right) Athabasca River basins. The 10- and 20-yr return events are indicated with vertical lines; sample size and confidence bands are the same as Fig. 9. Only the first WRF ensemble is shown; an equivalent figure with results from the alternate WRF ensemble is shown in Fig. S8. Note that none of the changes in the ARB is significant in the alternate WRF ensemble.

together with the more extreme quantiles of the associated cumulative distribution function; the semitransparent bands are $80 \%$ confidence intervals. Because the amount of data available to constrain the fit is relatively small, the tails of the distributions are not well constrained and the confidence intervals are strongly overlapping. We therefore only focus on return times of 10 and $20 \mathrm{yr}$ (indicated by vertical lines).

As in the preceding section, the most striking changes are seen in the Fraser River basin, while changes in the Athabasca River basin are not statistically significant until the end of the twenty-first century, and the increase in flood risk is less pronounced. The changes in the FRB are very similar in the alternate WRF ensemble, but the changes in the ARB are even smaller in the alternate ensemble and they are not statistically significant, even at the end of the twenty-first century [cf. Fig. S8 (top) in the supplemental material]. In the FRB, a 20-yr flooding event is projected to become a $10-\mathrm{yr}$ event, and a $10-\mathrm{yr}$ event a 4.5-yr event. This increase in water forcing may at first seem surprising, since historically the highest levels of water input would have occurred in spring, driven by rapid snowmelt or rain-on-snow events, and snowmelt volume is projected to decrease significantly by the end of the twenty-first century. The largest increase in water forcing in the FRB, however, is seen in fall; indeed, virtually all the major events that occur at the end of the century in the FRB occur in fall, when the 
rainy season begins in British Columbia. In the ARB, some of the declining snowmelt events are being replaced by (early) summer precipitation events. It is also interesting to note that in both basins, if changes occur, they occur in the main body of the distribution, and only to a lesser extent in the extreme quantiles. This may be a sampling artifact or due to the choice of a Gumbel distribution (i.e., the shape parameter is zero), but there is also a plausible physical explanation for this behavior: snowmelt can cause very large amounts of excess water when it coincides with heavy rain (as in rain-onsnow events), which was likely responsible for the largest flooding events in the past; however, with the significantly reduced snowpack at the end of the century, this is unlikely to result in large-scale flooding. Rain-dominated events in fall, on the other hand, are unlikely to coincide with (or trigger) significant snowmelt.

Monthly averages may not be the most relevant measure, because of the steep topography in the Fraser River basin, which would cause water masses to drain faster than in the prairies. Therefore we have also conducted a preliminary analysis of 5-day averaged water forcing (instead of monthly): the changes are qualitatively the same, but generally larger in magnitude, especially at midcentury and in the extreme quantiles (but changes in the ARB remain insignificant). We also note that the changes in pentad precipitation extremes in fall at the coast are very similar to the changes in 5-day water forcing over the FRB (not shown).

The finding that flood risk in fall may increase in the FRB is consistent with the results of Salathé et al. (2014), who employed a surface hydrologic model for the Columbia River basin forced by dynamically downscaled climate projection for a midcentury period.

\section{Summary and conclusions}

We have presented dynamically downscaled highresolution hydroclimate projections for western Canada, with an analysis of hydrological impacts in two major river basins, the Fraser River basin and the Athabasca River basin. This paper extends the preliminary results of Erler et al. (2015) in three important ways: 1 ) we have extended the simulations to the end of the twenty-first century; 2) we have added an additional WRF ensemble, which employs a different moist physics configuration; and 3) we explicitly consider changes in flood and drought risk as well as future water supply. Compared to CESM, WRF significantly improves the representation of orographic precipitation and the variation across the seasonal cycle. Nevertheless, precipitation in the rain shadow of the Rocky Mountains is still overestimated. Both WRF configurations also suffer from a cold bias in spring due to delayed snowmelt, and the alternate WRF configuration also has a significant solar radiation bias at the surface, likely because of lower cloud cover. An improved representation of snow physics and higher resolution to better resolve orographic precipitation in the Coast and Rocky Mountains would likely improve the simulations further. Only the RCP8.5 greenhouse gas scenario was considered.

By the end of the twenty-first century, the precipitation increase is approximately $20 \%$ annually. At the coast the precipitation maximum occurs in fall, where an even stronger increase of $30 \%$ is seen; the precipitation minimum at the coast is in summer, where no change is projected. The situation is the opposite in the Canadian Prairies, where the precipitation peak is in summer, and the increase is relatively uniform. An average warming of $4.8^{\circ} \mathrm{C}$ is projected by the end of the century, with considerable amplification in polar regions in winter and at high elevations in summer (the latter is not resolved by CESM). Changes by midcentury are to a good approximation about half the magnitude of changes at the end of the century.

The most important projected change by the end of the twenty-first century in the Fraser River basin is a significant shift from solid to liquid precipitation. The projected increase in annual net precipitation is $20 \%$, with $\pm 10 \%$ variability between ensemble members; a warming of $4.9^{\circ} \mathrm{C}$ is projected. The seasonal snowpack is likely to shrink by as much as $50 \%$ by the end of the century, but interannual variability and differences between ensemble members are large, possibly due to the effect of the snow-albedo feedback on spring temperatures, as well as decadal modes of climate variability, such as the Pacific decadal oscillation. The net effect is likely going to be a large reduction in the amplitude of the seasonal cycle of runoff (streamflow), including a significant reduction in the meltwater driven peak flow in early summer. Furthermore, we find that soil moisture in the Fraser River basin decreases significantly in late summer, because of earlier snowmelt and increased evaporative demand (and no increase in precipitation). An analysis of peak water forcing shows that, even though snowmelt decreases substantially in the Fraser River basin, the increase in fall precipitation will likely lead to an overall increase in the risk of moderate large-scale flooding (a 20-yr event would become a 10-yr event).

In the Athabasca River basin the projected total precipitation increase by the end of the century is also about $20 \%$ in the ensemble mean, with individual ensemble members again ranging from $10 \%-30 \%$. The projected warming is $4.2^{\circ} \mathrm{C}$ but, unlike in the $\mathrm{FRB}$, the 
amount of solid precipitation changes little because winters remain much colder on account of the continental climate. Based on the projections presented here, the most significant climate change impact in the ARB may be a somewhat increased risk of flooding, especially in early summer, because of higher precipitation and runoff generation $(\sim 15 \%)$. However, at this point, based on the two WRF ensembles described here, there is no indication for a reduction in soil moisture or an increased risk of drought in the ARB.

Finally we note that the regions and seasons with the largest projected changes are also often those with the largest biases. However, the mechanisms associated with these changes are physically plausible and the effect of the biases was accounted for in the interpretation. A fundamental uncertainty limiting the predictive power of the projections presented here is also the magnitude of natural (decadal) variability, and the hydroclimatic variables most relevant for water resources, namely snowmelt and net precipitation, are also among those with the highest variability. An analysis of climate variability in relation to major climate modes has been conducted by Erler et al. (2015). The effect of natural variability is stronger during the midcentury period as a result of the weaker climate change signal, but as the range of annual water supply or flood risk shows, it remains highly relevant at the end of the twenty-first century. This clearly underscores the need for larger ensembles and the application of a probabilistic approach to interpretation.

In summary, based on the simulations presented here, we conclude that climate change impacts in Alberta (east of the Rocky Mountains, including the ARB) are likely benign, whereas British Columbia and the FRB will potentially experience significant and severe changes, ranging from late summer drought in the interior to large-scale flooding at the coast. Furthermore, we expect the annual water supply to increase in most major river basins in western Canada, but interannual variability may also increase.

Acknowledgments. The simulations presented in this paper were performed on the SciNet High Performance Computing facility at the University of Toronto, which is a component of the Compute Canada HPC platform. The authors thank Dr. J. Gula for assistance with the initial setup of the modeling chain and Dr. D. Gruner and the SciNet team for assistance during the setup and operation of WRF. Furthermore the assistance of Dr. M. d'Orgeville and Dr. G. Vettoretti in providing and processing CESM data was invaluable and is gratefully acknowledged. ARE was partially supported by a SOSCIP Graduate Student Fellowship as well as an OCE post-doctoral fellowship.
The research of WRP at the University of Toronto is supported by NSERC Discovery Grant 9627.

\section{REFERENCES}

Abatzoglou, J. T., D. E. Rupp, and P. W. Mote, 2014: Seasonal climate variability and change in the Pacific Northwest of the United States. J. Climate, 27, 2125-2142, doi:10.1175/ JCLI-D-13-00218.1.

Burn, D. H., 2008: Climatic influences on streamflow timing in the headwaters of the Mackenzie River Basin. J. Hydrol., 352, 225-238, doi:10.1016/j.jhydrol.2008.01.019.

Christensen, J. H., and Coauthors, 2014: Climate phenomena and their relevance for future regional climate change. Climate Change 2013: The Physical Science Basis, T. F. Stocker et al., Eds., Cambridge University Press, 1217-1308.

Cook, B. I., T. R. Ault, and J. E. Smerdon, 2015: Unprecedented 21st century drought risk in the American Southwest and central plains. Sci. Adv., 1, e1400082, doi:10.1126/sciadv.1400082.

Dai, A., 2011: Drought under global warming: A review. Wiley Interdiscip. Rev.: Climate Change, 2, 45-65, doi:10.1002/ wcc.81.

Daly, C., M. Halbleib, J. I. Smith, W. P. Gibson, M. K. Doggett, G. H. Taylor, J. Curtis, and P. P. Pasteris, 2008: Physiographically sensitive mapping of climatological temperature and precipitation across the conterminous United States. Int. J. Climatol., 28, 2031-2064, doi:10.1002/joc.1688.

Das, T., D. W. Pierce, D. R. Cayan, J. A. Vano, and D. P. Lettenmaier, 2011: The importance of warm season warming to western U.S. streamflow changes. Geophys. Res. Lett., 38, L23403, doi:10.1029/2011GL049660.

Deser, C., A. Phillips, V. Bourdette, and H. Teng, 2012: Uncertainty in climate change projections: The role of internal variability. Climate Dyn., 38, 527-546, doi:10.1007/ s00382-010-0977-x.

Efron, B., and R. J. Tibshirani, 1994: An Introduction to the Bootstrap. CRC Press, $456 \mathrm{pp}$.

Eggert, B., P. Berg, J. Haerter, D. Jacob, and C. Moseley, 2015: Temporal and spatial scaling impacts on extreme precipitation. Atmos. Chem. Phys., 15, 5957-5971, doi:10.5194/ acp-15-5957-2015.

Endo, H., A. Kitoh, T. Ose, R. Mizuta, and S. Kusunoki, 2012: Future changes and uncertainties in Asian precipitation simulated by multiphysics and multi-sea surface temperature ensemble experiments with high-resolution Meteorological Research Institute atmospheric general circulation models (MRI-AGCMs). J. Geophys. Res., 117, D16118, doi:10.1029/ 2012JD017874.

Erler, A. R., and W. R. Peltier, 2016: Projected changes in precipitation extremes for western Canada based on high-resolution regional climate simulations. J. Climate, 29, 8841-8863, doi:10.1175/JCLI-D-15-0530.1.

_ _ _ and M. d'Orgeville, 2015: Dynamically downscaled high-resolution hydroclimate projections for western Canada. J. Climate, 28, 423-450, doi:10.1175/JCLI-D-14-00174.1.

Gent, P. R., and Coauthors, 2011: The Community Climate System Model version 4. J. Climate, 24, 4973-4991, doi:10.1175/ 2011JCLI4083.1.

Grell, G. A., and D. Dévényi, 2002: A generalized approach to parameterizing convection combining ensemble and data assimilation techniques. Geophys. Res. Lett., 29, 1693, doi:10.1029/2002GL015311. 
Gula, J., and W. R. Peltier, 2012: Dynamical downscaling over the Great Lakes Basin of North America using the WRF regional climate model: The impact of the Great Lakes system on regional greenhouse warming. J. Climate, 25, 7723-7742, doi:10.1175/JCLI-D-11-00388.1.

Harris, I., P. D. Jones, T. J. Osborn, and D. H. Lister, 2014: Updated high-resolution grids of monthly climatic observationsThe CRU TS3.10 dataset. Int. J. Climatol., 34, 623-642, doi:10.1002/joc.3711.

Herring, S. C., M. P. Hoerling, T. C. Peterson, and P. A. Stott, 2014: Explaining extreme events of 2013 from a climate perspective. Bull. Amer. Meteor. Soc., 95, S1-S104, doi:10.1175/ 1520-0477-95.9.S1.1.

Hong, S.-Y., and J.-O. J. Lim, 2006: The WRF single-moment 6-class microphysics scheme (WSM6). Asia-Pac. J. Atmos. Sci., 42, 129-151.

Iacono, M. J., J. S. Delamere, E. J. Mlawer, M. W. Shephard, S. A. Clough, and W. D. Collins, 2008: Radiative forcing by longlived greenhouse gases: Calculations with the AER radiative transfer models. J. Geophys. Res., 113, D13103, doi:10.1029/ 2008JD009944.

Kain, J. S., 2004: The Kain-Fritsch convective parameterization: An update. J. Appl. Meteor., 43, 170-181, doi:10.1175/ 1520-0450(2004)043<0170:TKCPAU>2.0.CO;2.

Katz, R. W., M. B. Parlange, and P. Naveau, 2002: Statistics of extremes in hydrology. Adv. Water Resour., 25, 1287-1304, doi:10.1016/S0309-1708(02)00056-8.

Kerkhoven, E., and T. Y. Gan, 2011: Differences and sensitivities in potential hydrologic impact of climate change to regionalscale Athabasca and Fraser River basins of the leeward and windward sides of the Canadian Rocky Mountains respectively. Climatic Change, 106, 583-607, doi:10.1007/ s10584-010-9958-7.

Koster, R. D., and Coauthors, 2004: Regions of strong coupling between soil moisture and precipitation. Science, 305, 11381140, doi:10.1126/science.1100217.

Leong, D. N., and S. D. Donner, 2015: Climate change impacts on streamflow availability for the Athabasca oil sands. Climatic Change, 133, 651-663, doi:10.1007/ s10584-015-1479-y.

Lucas-Picher, P., D. Caya, R. de Elía, and R. Laprise, 2008: Investigation of regional climate models internal variability with a ten-member ensemble of 10-year simulations over a large domain. Climate Dyn., 31, 927-940, doi:10.1007/ s00382-008-0384-8.

Maraun, D., and Coauthors, 2010: Precipitation downscaling under climate change: Recent developments to bridge the gap between dynamical models and the end user. Rev. Geophys., 48, RG3003, doi:10.1029/2009RG000314.

Mearns, L., and Coauthors, 2013: Climate change projections of the North American Regional Climate Change Assessment Program (NARCCAP). Climatic Change, 120, 965-975, doi:10.1007/s10584-013-0831-3.

Morrison, H., G. Thompson, and V. Tatarskii, 2009: Impact of cloud microphysics on the development of trailing stratiform precipitation in a simulated squall line: Comparison of oneand two-moment schemes. Mon. Wea. Rev., 137, 991-1007, doi:10.1175/2008MWR2556.1.

Mote, P. W., and E. P. Salathé, 2010: Future climate in the Pacific Northwest. Climatic Change, 102, 29-50, doi:10.1007/ s10584-010-9848-z.

Overpeck, J. T., 2013: Climate science: The challenge of hot drought. Nature, 503, 350-351, doi:10.1038/503350a.
Pachauri, R. K., and Coauthors, 2014: Climatic Change 2014: Synthesis Report. IPCC, $151 \mathrm{pp}$.

Pollock, E. W., and A. B. G. Bush, 2013: Changes in snow mass balance in the Canadian Rocky Mountains caused by $\mathrm{CO}_{2}$ rise: Regional atmosphere model results. Atmos.-Ocean, 51, 505521, doi:10.1080/07055900.2013.852964.

Rupp, D. E., J. T. Abatzoglou, and P. W. Mote, 2017: Projections of 21st century climate of the Columbia River basin. Climate Dyn., 49, 1783-1799, doi:10.1007/s00382-016-3418-7.

Salathé, E. P., L. R. Leung, Y. Qian, and Y. Zhang, 2010: Regional climate model projections for the State of Washington. Climatic Change, 102, 51-75, doi:10.1007/s10584-010-9849-y.

- A. F. Hamlet, C. F. Mass, S.-Y. Lee, M. Stumbaugh, and R. Steed, 2014: Estimates of twenty-first-century flood risk in the Pacific Northwest based on regional climate model simulations. J. Hydrometeor., 15, 1881-1899, doi:10.1175/ JHM-D-13-0137.1.

Sauchyn, D. J., J.-M. St-Jacques, and B. H. Luckman, 2015: Longterm reliability of the Athabasca River (Alberta, Canada) as the water source for oil sands mining. Proc. Natl. Acad. Sci. USA, 112, 12 621-12 626, doi:10.1073/pnas.1509726112.

Schindler, A., A. Toreti, M. Zampieri, E. Scoccimarro, S. Gualdi, S. Fukutome, E. Xoplaki, and J. Luterbacher, 2015: On the internal variability of simulated daily precipitation. J. Climate, 28, 3624-3630, doi:10.1175/JCLI-D-14-00745.1.

Schneider, U., A. Becker, P. Finger, A. Meyer-Christoffer, M. Ziese, and B. Rudolf, 2013: GPCC's new land surface precipitation climatology based on quality-controlled in situ data and its role in quantifying the global water cycle. Theor. Appl. Climatol., 115, 15-40, doi:10.1007/ s00704-013-0860-x .

Seneviratne, S. I., T. Corti, E. L. Davin, M. Hirschi, E. B. Jaeger, I. Lehner, B. Orlowsky, and A. J. Teuling, 2010: Investigating soil moisture-climate interactions in a changing climate: A review. Earth Sci. Rev., 99, 125-161, doi:10.1016/ j.earscirev.2010.02.004.

Šeparović, L., A. Alexandru, R. Laprise, A. Martynov, L. Sushama, K. Winger, K. Tete, and M. Valin, 2013: Present climate and climate change over North America as simulated by the fifthgeneration Canadian regional climate model. Climate Dyn., 41, 3167-3201, doi:10.1007/s00382-013-1737-5.

Shrestha, R. R., M. A. Schnorbus, A. T. Werner, and A. J. Berland, 2012: Modelling spatial and temporal variability of hydrologic impacts of climate change in the Fraser River basin, British Columbia, Canada. Hydrol. Processes, 26, 1840-1860, doi:10.1002/hyp.9283.

Smirnov, N. V., 1939: On the estimation of the discrepancy between empirical curves of distribution for two independent samples. Bull. Math. Univ. Moscou, 2 (2), 3-14.

, 1948: Table for estimating the goodness of fit of empirical distributions. Ann. Math. Stat., 19, 279-281, doi:10.1214/aoms 1177730256.

Steinskog, D. J., D. B. Tjøstheim, and N. G. Kvamstø, 2007: A cautionary note on the use of the Kolmogorov-Smirnov test for normality. Mon. Wea. Rev., 135, 1151-1157, doi:10.1175/ MWR3326.1.

Stott, P., 2015: Attribution: Weather risks in a warming world. Nat. Climate Change, 5, 517-518, doi:10.1038/nclimate 2640 .

Teutschbein, C., and J. Seibert, 2012: Bias correction of regional climate model simulations for hydrological climate-change impact studies: Review and evaluation of different methods. J. Hydrol., 456-457, 12-29, doi:10.1016/ j.jhydrol.2012.05.052. 
- and — 2013: Is bias correction of regional climate model (RCM) simulations possible for non-stationary conditions? $\mathrm{Hy}$ drol. Earth Syst. Sci., 17, 5061-5077, doi:10.5194/hess-17-5061-2013.

_, F. Wetterhall, and J. Seibert, 2011: Evaluation of different downscaling techniques for hydrological climate-change impact studies at the catchment scale. Climate Dyn., 37, 20872105, doi:10.1007/s00382-010-0979-8.

Tewari, M., and Coauthors, 2004: Implementation and verification of the unified NOAH land surface model in the WRF model. 20th Conf. on Weather Analysis and Forecasting/16th Conf. on
Numerical Weather Prediction, Seattle, WA, Amer. Meteor. Soc., 14.2a. [Available online at https://ams.confex.com/ams/ 84Annual/techprogram/paper_69061.htm.]

von Storch, H., and F. W. Zwiers, 2002: Statistical Analysis in Climate Research. Cambridge University Press, 495 pp.

Wang, W., and Coauthors, 2012: ARW version 3 modeling system user's guide (January 2012). Mesoscale \& Miscroscale Meteorology Division, National Center for Atmospheric Research. [Available online at http://www2.mmm.ucar.edu/wrf/users/ docs/user_guide_V3/contents.html.] 